\title{
Current research and industrial application of laser powder directed energy deposition
}

\author{
Gabriele Piscopo $^{1}\left[\right.$ D $\cdot$ Luca Iuliano ${ }^{1}$
}

Received: 3 August 2021 / Accepted: 18 December 2021 / Published online: 26 January 2022

(c) The Author(s) 2022

\begin{abstract}
Additive Manufacturing (AM) technologies are recognized as the future of the manufacturing industry thanks to their possibilities in terms of shape design, part functionality, and material efficiency. The use of AM technologies in many industrial sectors is growing, also due to the increasing knowledge regarding the AM processes and the characteristics of the final part. One of the most promising AM techniques is the Directed Energy Deposition (DED) that uses a thermal source to generate a melt pool on a substrate into which metal powder is injected. The potentialities of DED technology are the ability to process large build volumes ( $>1000 \mathrm{~mm}$ in size), the ability to deliver the material directly into the melt pool, the possibility to repair existing parts, and the opportunity to change the material during the building process, thus creating functionally graded material. In this paper, a review of the industrial applications of Laser Powder Directed Energy Deposition (LP-DED) is presented. Three main applications are identified in repairing, designed material, and production. Despite the enormous advantages of LP-DED, from the literature, it emerges that the most relevant application refers to the repairing process of high-value components.
\end{abstract}

Keywords Additive manufacturing · Directed energy deposition · Industrial applications $\cdot$ Repair application · Functionally graded materials $\cdot$ Product remanufacturing

\section{Introduction}

The improvement of Additive Manufacturing (AM) systems and the increasing knowledge on the properties of the produced parts drive the use of AM processes for the production of final components. Automotive [1, 2], medical [3, 4], and aerospace [5-7] are only a few of the sectors in which AM processes are successfully used [8]. The common factors of these sectors are the geometrical complexity and the small to medium batch production which makes production by AM economically convenient [9-11].

Considering the processes that use metal alloys as feedstock material, according to ASTM [12], the main metal AM processes are Powder Bed Fusion (PBF) processes, which

Gabriele Piscopo

gabriele.piscopo@polito.it

Luca Iuliano

luca.iuliano@polito.it

1 Department of Management and Production Engineering (DIGEP), Politecnico Di Torino, C.so Duca degli Abruzzi, 24, Torino 10129 , Italy include Laser-Powder Bed Fusion (L-PBF) and ElectronPowder Bed Fusion (E-PBF), and Directed Energy Deposition (DED) processes.

From the literature, it is possible to observe that, despite the high level of industrialization of powder bed processes, they can be used only for the production of small/medium components, with a maximum size of $400 \mathrm{~mm}[13,14]$. DED processes allow overcoming this problem since the deposited dimension can reach up to $3000 \mathrm{~mm}$ in size. The main DED systems are listed in Table 1, with the indication of the building volume. Another advantage of the DED process with respect to the other metal AM processes is that the substrate could coincide with the surface of an existing component, and this characteristic is very powerful for the repair application. Moreover, it is also possible to change the material during the deposition process, thus obtaining components that are characterized by different properties in different areas.

Conversely to PBF processes, the DED process is not a consolidated process and therefore is considered premature for industrial production [15-17]. In addition, also the number of DED systems installed around the world is still low, as depicted in the graph in Fig. 1. This graph illustrates the 
Table 1 Main DED manufacturer and systems considering the process and the building volume [13]

\begin{tabular}{lll}
\hline Manufacturer (system) & Process & Build volume $\left.\mathbf{( m m}^{3}\right)$ \\
\hline Accufusion laser consolidation & LC & $1000 \times 1000 \times 1000$ \\
DM3D (DMD 500D) & DED & $1219 \times 1219 \times 600$ \\
DM3D (DMD 500D) & DED & $800 \times 800 \times 430$ \\
DMG MORI (LASERTEC 65) & DED & $735 \times 650 \times 560$ \\
DMG MORI (LASERTEC 125) & DED & $1335 \times 1250 \times 900$ \\
OPTOMEC (LENS 850-R) & LENS & $900 \times 1500 \times 900$ \\
OPTOMEC (LENS CS 800) & LENS & $800 \times 600 \times 600$ \\
OPTOMEC (LENS CS 600) & LENS & $600 \times 400 \times 400$ \\
POM DMD (66R) & DMD & $3200 \times 3670 \times 360$ \\
Prima Additive (LaserDyne 430) & LMD & $585 \times 400 \times 500$ \\
Prima Additive (LaserDyne 795) & LMD & $1000 \times 1000 \times 1000$ \\
Sciaky (NG1) EBFFF & EBDM & $762 \times 483 \times 508$ \\
TRUMPF (TruLaser Cell 3000) & LD & $800 \times 600 \times 400$ \\
TRUMPF (TruLaser Cell 7040) & LD & $4000 \times 1500 \times 750$ \\
\hline
\end{tabular}

industrial distribution of metal AM systems sold and shows that the metal AM market is dominated by the powder bed fusion processes with a percentage of $82 \%[18,19]$. Directed energy deposition is the second technology for number of systems sold with a percentage of only $8 \%$ (ten times lower with respect to PBF processes).

However, it should be noted that the industrial interest regarding DED processes is growing exponentially [20,21] and it is therefore important to highlight the main industrial achievement obtained nowadays and identify the future trends of this technology.

Several reviews are available regarding the DED process on the physics of the process [15, 22, 23], on the repair operations [24], on the monitoring technologies [25], and the alloys processed by DED [26-29]. However, all of them focused on the characterization of the parts and the effect of process parameters. This review aims to illustrate the technological readiness level of the DED technology and the feasibility of applying DED in industrial production. Thus, current successful industrial cases are described, where the DED process was applied. The review could guide researchers and manufacturers to the next steps for more in-depth industrialization of the technology.

There are several DED processes that differ in the feedstock material, which can be in the form of powder or wire, and for the energy source that can be a laser or an electron beam. Nevertheless, powder material and laser energy source are the most common equipment used in the industry [30]. As a consequence, the primary scope of this work is to describe the main industrial applications of directed energy deposition processes that use powder as feedstock and laser as energy source, and this technology in the following is referred as Laser Powder Directed Energy Deposition (LPDED) process. Hence, firstly, a brief description of the LPDED process and system is presented. Then, the applications are described focusing on repairing operations, production of functionally graded and designed materials, and production of near net shape components.

\section{LP-DED process}

A schematic representation of an LP-DED system is depicted in Fig. 2. It is composed of four fundamental elements: the laser, the motor, the feedstock feed mechanism,
Fig. 1 Distribution of metal additive manufacturing systems in the market in 2019 [18]

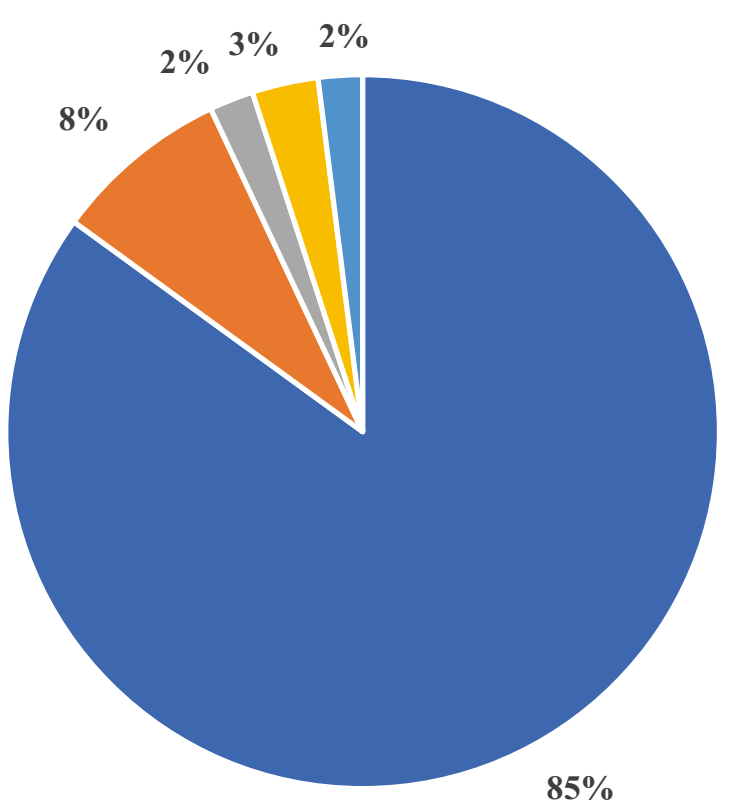

- Powder Bed Fusion

- Directed Energy Deposition

Metal FDM

Binder Jetting

- Other 
Fig. 2 Representation of a general laser powder directed energy deposition (LP-DED) system [34]

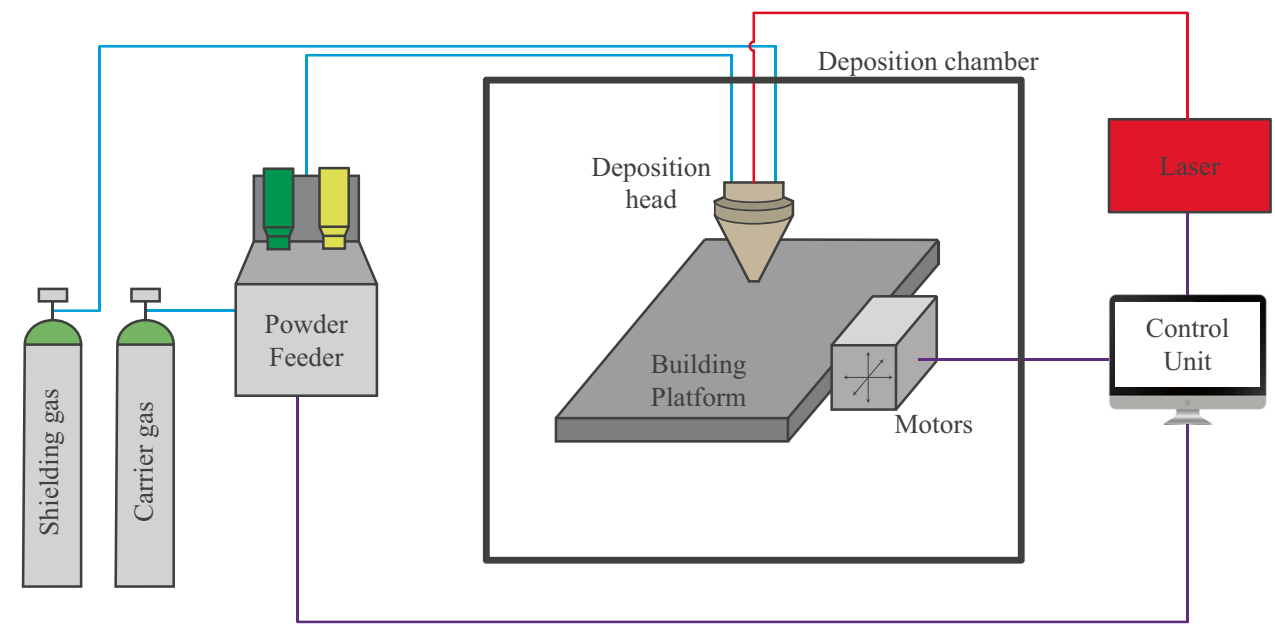

in turn composed by the powder feeder and by the deposition head, and the control unit [31].

In the LP-DED process, a focused laser beam is used to produce a melt pool on a substrate or building platform. Then, a nozzle, or deposition head, feeds the powder material into the generated melt pool by means of carrier gas. When the powder material enters into the melt pool, it melts instantaneously increasing the volume of liquid material. When the laser moves away, the molten material solidifies quickly and a raised track is obtained [22]. The working area, near the generated melt pool, is protected from oxidation using a shielding gas [32]. Both the carrier gas and the shielding gas are typically argon [30]. The relative movement is achieved by moving the deposition head or by moving the substrate $[22,30,32]$. Repeating this operation several times, it is possible to obtain three-dimensional complex components. Some systems are equipped with additional axes that allow to tilt and rotate the building platform, making possible the production of overhanging features [5, 33].

Based on the physics of the LP-DED process, several technologies have been developed [22, 30, 32, 35, 36]. The most used LP-DED technologies are the Directed Light Fabrication (DLF) process developed at Los Alamos National Laboratory [37, 38], the Laser Engineered Net Shaping (LENS®) process developed at Sandia National Laboratories [39], and the Direct Metal Deposition (DMD ${ }^{\mathrm{TM}}$ ) process developed by POM Group [40-43]. Differences between DLF, LENS, and DMD processes include laser power, laser spot size, laser type, powder delivery method, inert gas delivery method, feedback control system, and the motion control used [30]. It was demonstrated that DLF is a suitable production technology for the production of near net shape complex components of refractory metals [44] and stainless steel alloys [45]. In DLF, a glove box is used to maintain the level of oxygen under $10 \mathrm{ppm}$ to avoid problems related to oxidation phenomena. DLF uses a controlled sequence of tool paths derived from the CAD data to define the motion of the substrate. This approach is similar to that used in Computer Numerical Control (CNC) programming; however, in DLF, a postprocess is required to convert the path of the deposition head and the control of the powder feed into a G-code [33, 37, 46]. Differently from DLF, in the LENS process, the motion path derives from the STL file as in common AM processes [22, 33]. In the LENS process, the powder is delivered into the deposition zone using a deposition head with four axisymmetric nozzles [15, 22]. The DMD process uses a patented concentric nozzle [41] to deliver the metal powder into the working area. Furthermore, the DMD system is equipped with a feedback system that provides a closed-loop for the control of the dimensions of the deposited part [40, 43].

\section{Repair and maintenance}

The damage of a component could be induced by several phenomena like corrosion, thermal stress, and variable thermal cycle and impact $[5,32]$. The damaged components are typically replaced by new parts; however, under certain circumstances, it is more convenient to repair them. This is the case when the repaired components are characterized by high economic value. This high value derives from the complex operations required to produce the component and from the valuable material used [47]. For this reason, repairing these components could mean significant cost savings [5, 47]. For example, the US Army's Anniston Deport (ANAD) estimated an annual cost saving up to $\$ 5$ million repairing Honeywee gas turbine components for the M1 Abrams tank [48].

In the industry, Tungsten Inert Gas (TIG) welding was the first technique used for repairing damaged components [5, 49]. Despite its relatively simple applicability, the TIG process induces a huge amount of heat in the repaired 
component, and this leads to high residual stresses and distortions [50]. On the other hand, Plasma Transferred Arc Welding (PTAW) and Electron Beam Welding (EBW) processes satisfy the requirement of a low heat input; however, their equipment is more complex and expensive $[49,51,52]$.

To date, among other technologies, the LP-DED process is one of the most used processes to repair damaged components [53, 54] thanks to the less heat input [55-57], less warpage and distortions [24], and higher precision $[58,59]$ compared to conventional processes. Also, the mechanical properties of the repaired parts are promising and attractive in fact, as reported in Table 2, the mechanical performance in terms of yield strength and ultimate tensile strength are comparable with the bulk material; however, the elongation is quite lower. Hence, further researches are necessary.

Moreover, the repair operation using the LP-DED process requires a huge interaction between different disciplines, such as CAD/CAM software and inspection systems, and a high level of operators' knowledge [62].

According to Ruiz-Salas et al. [62] and Yilmaz et al. [63], the repair operation of a damaged component follows these different steps:

- Obtaining geometry of the damaged part through 3D digitalization

- Comparison of the nominal and the actual geometry to highlight the damaged area

- Evaluation of the repaired area and surface preparation

- Material characterization, optimizing the process parameters

- Tool path definition through CAM software

- Affected area reparation

- Machining the repaired area

- 3D digitalization of the repaired part

- Comparison of the repaired geometry with the original CAD model to validate the reparation

In the following paragraphs, the main achievements of repair operation using the LP-DED process are described, highlighting the industrial sector that are the aerospace sector, the tooling sector, and the other sectors.

\subsection{LP-DED repair in the aerospace sector}

The aerospace sector is characterized by components produced using high-performance materials, such as Ti6Al4V and Inconel, that are very expensive due to difficulties in manufacturing and due to the complex geometry [64]. The possibility to drastically reduce the cost by repairing the damaged components instead of replacing them is the driving force of the repair application in this sector $[5,65]$. The LP-DED process thanks to its high precision and to the minimal distortion induced in the repaired component [24] allows obtaining acceptable results in terms of dimensional deviation and metallurgical bonding and hence turns out to be the optimal repair process in the aerospace sector [65]. Moreover, the use of the LP-DED process in the aerospace sector could lead to environmental benefits due to less waste of material as demonstrated by Wilson et al. [53] during the repair process of a damaged turbine blade (Fig. 3). In their work, an Optomec LENS 750 machine was used to repair a 316L stainless steel blade damaged in the tip portion. The repaired blade showed good results with an accuracy of about $0.03 \mathrm{~mm}$ with respect to the nominal geometry. Moreover, the Life Cycle Assessment (LCA) showed the effectiveness of using the LP-DED process in repair operations [66]. In detail, when the repair volume was of about $10 \%$, the use of the LP-DED process resulted in an improvement in the carbon footprint of $45 \%$ and a total energy saving of about $36 \%$ with respect to replacing with a new one. Tensile tests were also performed on undamaged and repaired samples. Results showed that the Ultimate Tensile Strength (UTS) of the repaired and the undamaged sample are $793 \mathrm{MPa}$ and $815 \mathrm{MPa}$ respectively and these values are consistent with the annealed bar. In addition, it was noted that both repaired and undamaged tensile samples broke away from the central and the repaired region.

However, in the aerospace sector, it is well known that the quality of the part is the priority; hence, tens of feasibility researches were performed and applied. For this reason, the feasibility of the repairing application of the LP-DED process has been studied by different researchers, both at academic and industrial levels, by testing case studies of industrial interest. For instance, Optomec [67] used the
Table 2 Comparison of mechanical properties between as-built and repaired LP-DED parts

\begin{tabular}{|c|c|c|c|c|c|}
\hline Material & Status & $\begin{array}{l}\text { Elongation, } \\
\varepsilon(\%)\end{array}$ & $\begin{array}{l}\text { Yield strength, } \\
\text { YS (MPa) }\end{array}$ & $\begin{array}{l}\text { Ultimate tensile } \\
\text { strength, UTS (MPa) }\end{array}$ & Ref \\
\hline \multirow[t]{2}{*}{316} & LP-DED AB & 64 & 340 & 550 & \multirow[t]{2}{*}[60]{} \\
\hline & LP-DED repaired & 37 & 342 & 647 & \\
\hline \multirow[t]{2}{*}{ IN625 } & LP-DED AB & 69 & 487 & 815 & \multirow[t]{2}{*}[53]{} \\
\hline & LP-DED repaired & 56 & 482 & 793 & \\
\hline \multirow[t]{2}{*}{ Ti6Al4V } & LP-DED AB & 12 & 920 & 1010 & \multirow[t]{2}{*}{ [61] } \\
\hline & LP-DED repaired & 5 & 940 & 1020 & \\
\hline
\end{tabular}


Fig. 3 a Damaged and b restored 316L turbine blade (dimensions in the cross-section view $20 \mathrm{~mm} \times 45 \mathrm{~mm}$ ) [53]

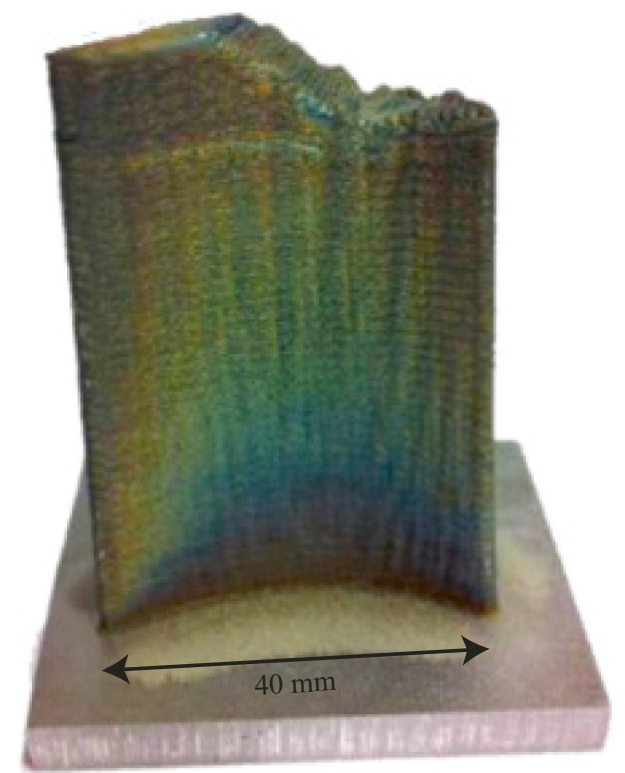

(a)

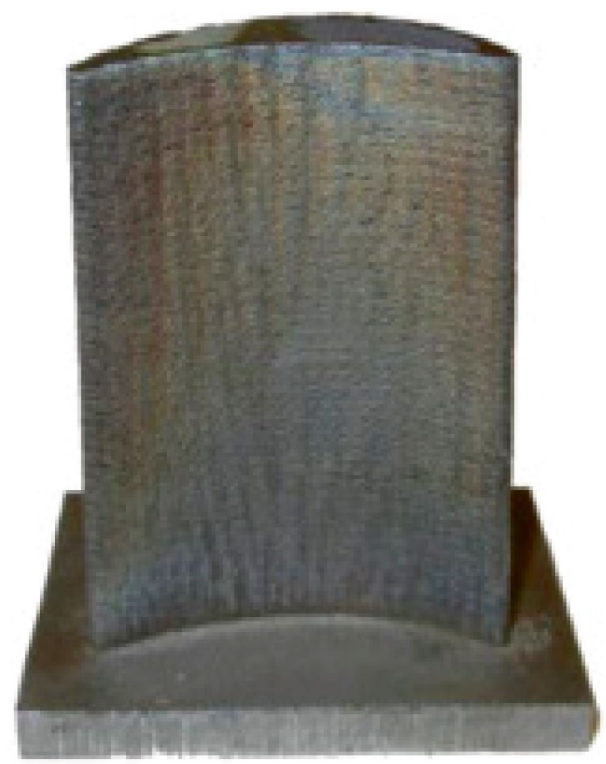

(b)
LP-DED process to repair an AM355 steel T700 blisk damaged due to the effect of erosion on the airfoil leading edges (Fig. 4). The repair operation was performed using a cobaltbased wear-resistant material and showed an attractive return of investment. The repair was mechanically verified with 50,000 cycles of low cycle fatigue spin test [68] and with $60,000 \mathrm{rpm}$ spin test $[67,68]$.

Gasser et al. [54] illustrated the main results obtained into one of the major European projects that is FANTASIA, regarding the use of the LP-DED process in repair and maintenance in turbo-engine applications. The main aspect faced in this project is the accuracy during the deposition. In addition to the accuracy, the results showed that the deposited material is characterized by adequate static and dynamic characteristics thanks to the obtained microstructure.

Figure 5a depicts a damaged HPT shroud of Rene N5 CFM56. The challenges during the repair operation were to spare the cooling holes and to avoid melting of the thin edges

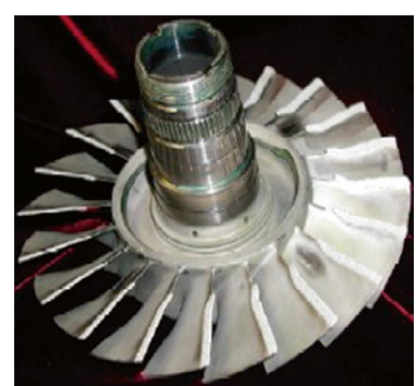

(a)

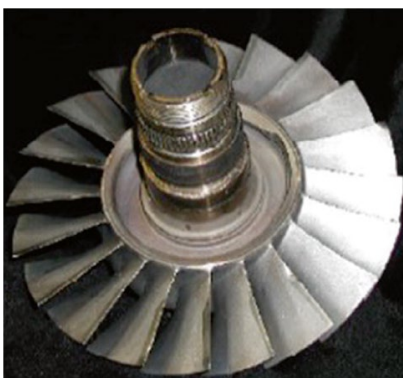

(b)
Fig. 4 a Damaged and b restored AM355 steel T700 blisk (courtesy of Optomec $($ ) [67] obtained in FANTASIA. In order to obtain the repaired surface, the damaged component was firstly scanned and then the data were used to generate the deposition path. The result, depicted in Fig. 5b, showed that LP-DED could be used to repair HPT shrouds with low dilution and good accuracy, lower than $0.15 \mathrm{~mm}$ [69].

The use of the LP-DED process was also certified by Rolls-Royce Deutschland for 15 different repair operations $[54,70]$. Two of the most significant examples are depicted in Figs. 6 and 7 respectively. Figure 6 shows a BR715 HPT case produced using a nickel alloy. During functioning, some features of this part such as bosses, flanges, and brackets are subjected to wear. LP-DED was successfully used to repair a nickel-based alloy Nimonic PE16 worn flange using Ni625 alloy. During the process, the oxidation phenomena were avoided by means of the shielding gas.

Figure 7 shows the damping wire grooves of a BR715 HPC front dump made of Ti6Al4V alloy. In this application, the component was repaired by local reconditioning of

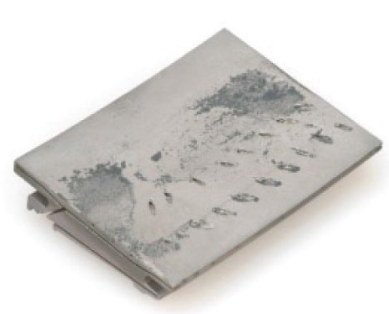

(a)

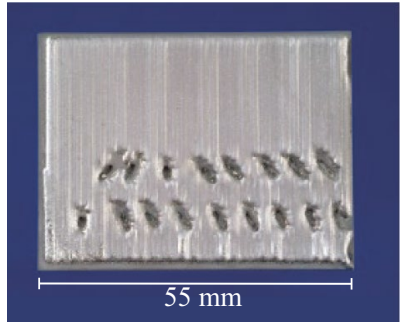

(b)
Fig. 5 CFM56 HPT shroud a before and b after laser metal deposition (LMD) process [54] 


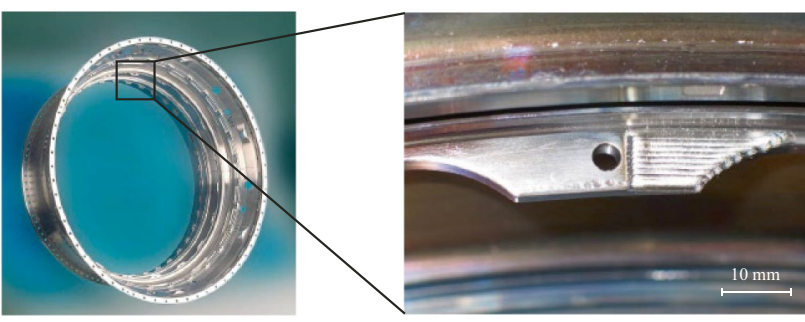

Fig. 6 Reparation of a BR715 HPT case flange using laser metal deposition process [54]

the groove wall. The application was characterized by two critical issues. The first is that the wall in front of the worn one must not be affected by the process. Moreover, it is necessary to consider that the working area is restricted due to the presence of the groove geometry. The LP-DED process allowed to overcome these issues; however, the quality of the repaired part has to be improved through the optimization of process parameters [71]. For example, Liu et al. [72] performed a preliminary work in order to investigate the capability of the LP-DED process to repair aluminium alloy aircraft structures. Results showed that good metallurgical bonding without cracks could be obtained with the proper combination of process parameters. However, due to the weak interface between the deposited material and the substrate, both the tensile strength and the fatigue life were lower compared to the properties of the substrate material. Hence, further investigations are required [72].

In addition to the process parameters, the deposition strategy is another factor that affects the part quality $[16,73]$. Petrat et al. [56] optimized the deposition strategy in order to minimize the dimensional deviation and to obtain a regular geometry during the repair operation of a gas turbine burner of Inconel 718. The repaired component was characterized by a circular geometry and the deposition strategy consists of circular paths with a variable starting point and, in the last layer, an inner and an outer circle track. Cobalt-based alloy was successfully used by Zhang et al. [74] to repair
H-13 tool steel samples. In their study, the distortion of the components was minimized using a continuous deposition strategy eliminating the accelerations and the decelerations of the deposition head. Results showed a good metallurgical bond between the substrate and the deposited material. Moreover, the repaired component exhibited a higher UTS and a lower value of ductility compared to those of the base component. Kistler et al. [75], repairing Ti6Al4V samples, analysed the effect of part thickness, deposition strategy, number of deposited layers, initial temperature, and interlayer dwell time on the quality of the repaired part. Results showed that the HAZ was mainly influenced by the part thickness; in particular, thick parts were characterized by a smaller HAZ with respect to thin parts. Porosity was only slightly influenced by the number of the deposited layers and increased with this number. Then, it was observed that the hardness was influenced by the initial temperature of the substrate and higher temperatures led to a lower value of hardness due to the smaller thermal gradient.

Qi et al. [76] in order to repair turbine engine compressor and blisk airfoils of Inconel 718 developed a geometrybased adaptive deposition strategy method. This method was based on analytical relationships that were introduced into the G-code in order to relate the movements of the deposition head to the part geometry. In particular, the analytical relations relate the process parameters to the deposited track. Therefore, on the basis of the geometry of the part to be repaired, the process parameters and the hatching distance were varied during the repair process. Nowotny et al. [58] repaired titanium blades on a rotor of an aircraft engine (Fig. 8a). The repair process was performed in a closed inert gas chamber in order to reduce the oxidation. The result of the repair operation is depicted in Fig. 8b. The selection of appropriate process parameters and deposition strategy allowed obtaining a fully dense and fine crystalline microstructure. The mechanical performances, in terms of tensile and fatigue strength, were at least equal to the base material. Finally, Nowotny et al. [58] showed that an integration between different systems, such as LP-DED and

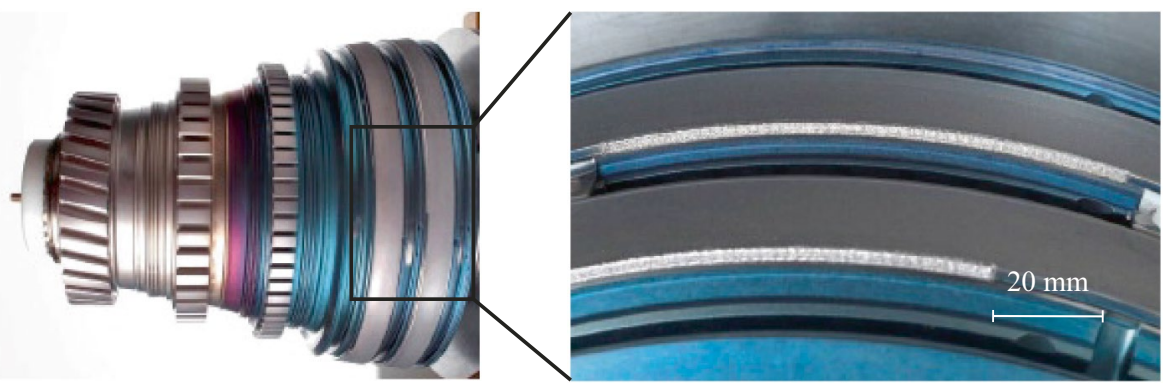

(a)

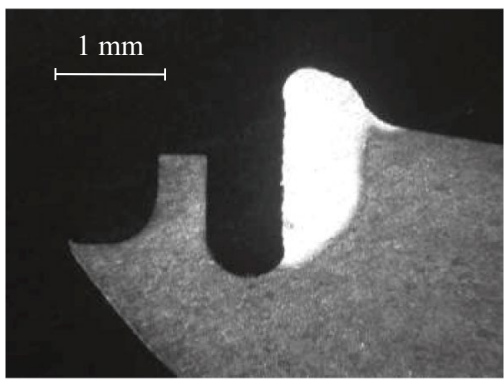

(b)

Fig. 7 a Ti6Al4V groove wall repair using LP-DED process and $\mathbf{b}$ cross-section of the repaired groove [54] 


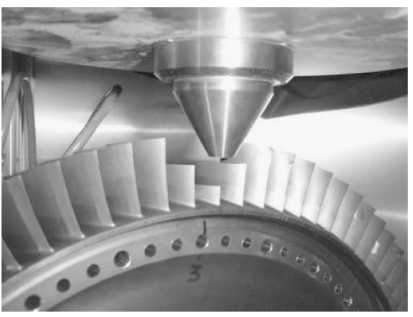

(a)

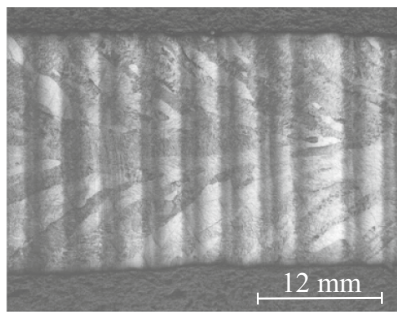

(b)
Fig. 8 a Repair operation of the titanium blade and $\mathbf{b}$ microstructure of the repaired blade [58]

milling, could lead to economic advantages [58]. The integration of different processes into a single fully integrated repair solution was analysed by Jones et al. [77]. This integration was achieved with the RECLAIM (REmanufacture of high-value products using a Combined LAser cladding, Inspection and Machining system) approach by designing a system with a modular tool holder capable of adapting to different tools. The validation was performed repairing a titanium turbine blade. The results showed that integrating LP-DED, scanning system and machining in a single machine, could open new repair possibilities and expand the success rate with minimum capital investment. Moreover, they showed that this approach simplifies the logistic by reducing the part transportation and that it could be used not only for turbine blade repairing but also for solving other additional defects.

\subsection{LP-DED repair of tools and moulds}

On dies and moulds, during their use, different types of defects, such as heat cracks and wear, could occur [78], and for this reason, they have a limited in-service lifetime [79]. One of the most challenging issues during the repair operation of dies and tools is related to the low weldability of the materials commonly used for their production [80]. In addition, due to the high carbon content and alloying elements, there is a high tendency to the formation of brittle phases [81].
The minimization of cracks was obtained by studying the effect of process parameters and the surface preheating. For example, Borrego et al. [82] depositing P20 alloy on H-13 tool steel substrate showed that the numbers of cracks and defects could be reduced through an optimization of the process parameters. In addition, they showed that the fatigue resistance is mainly influenced by the residual stresses. In fact, during the fatigue test at $R=0$, the repaired samples exhibited a significantly lower resistance. Instead, when the fatigue test was conducted at $R=0.4$, the non-repaired and the repaired samples showed a similar fatigue behaviour, and this was attributed to the high level of tensile residual stress. Then, Kattire et al. [83] repaired H-13 tool steel with CPM $9 \mathrm{~V}$ steel powder analysing the influence of process parameters on track geometry and track quality. Results showed that the main process parameters that affect the track geometry were laser power, travel speed, and powder feed rate; instead, the dilution was mainly affected by powder feed rate and gas flow rate. The mechanical characterization of the samples showed that in the deposited layer, compressive residual stresses were generated. Leunda et al. [84] varying the process parameters repaired heat cracks, caused by repetitive heating and cooling cycles [85], on Vanadis 4 die using Vanadis 4 and CPM 10 powder. Results showed that a good metallurgical bonding was obtained without defect, and this suggests that LP-DED can be successfully used to repair heat cracks. The microhardness of the repaired area was of about $700 \mathrm{HV} 0.3$, resulting slightly lower with respect to that of the base material. This was attributed to the similar microstructure observed in the repaired area and the base material; hence, Leunda et al. [84] suggested that LP-DED process can be used to repair tool steel die without modifying the mechanical characteristics. Lestan et al. [86] during the deposition of Metco $15 \mathrm{E}$, Colmony 88, and VIM CRU 20 powders on cast iron substrate showed that the formation of cracks was reduced by preheating the substrate.

Ren et al. [87] in order to improve the accuracy and the reliability of repair operations combined the use of adaptive zigzag tool path pattern with $3 \mathrm{D}$ alignment technology. The proposed repair strategy was tested on the die repair for
Fig. 9 Spartan Metal LLC die core $\mathbf{a}$ before repairing, $\mathbf{b}$ after LP-DED process, and $\mathbf{c}$ after finishing operations [87]

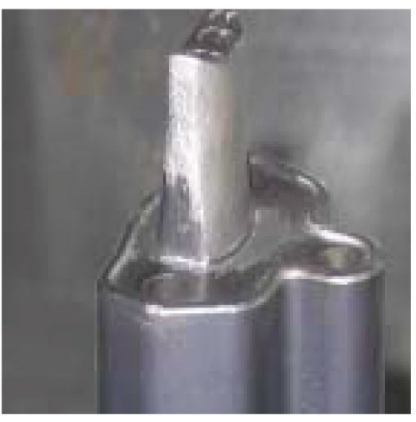

(a)

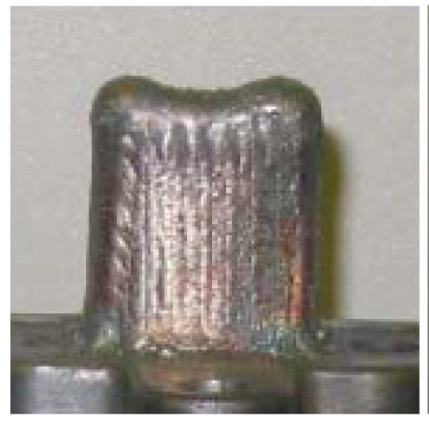

(b)

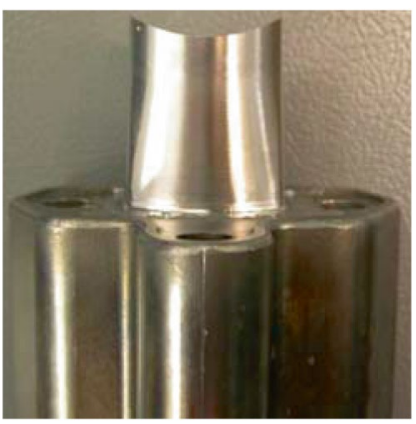

(c) 


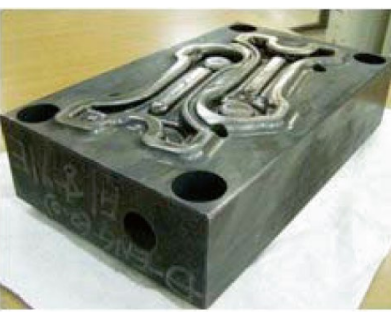

(a)

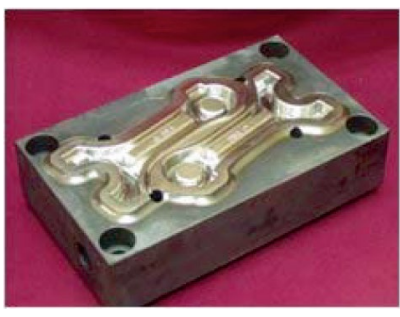

(b)
Fig. 10 a Damaged and b restored hot forging die [88]

Spartan Light Metal LLC. Figure 9 shows the damaged die core (left), the die after the deposition process (centre), and the die after the finishing operation (right). In their work, they demonstrated the capability of the LP-DED process for repair operation; moreover, a high thermal conductivity in the component produced by LP-DED was obtained compared to the original component and the component repaired using welding technologies.

In addition to the feasibility of the repair operation, a lot of works were focused on the sustainability and the environmental impact that derives from repair operation. The sustainability and the environmental impact were measured by different factors such as energy consumption, pollution, material waste, lead time, and cost [79, 80, 88-90]. The impact of these factors is usually investigated by Life Cycle Analysis (LCA) [91]. From an economic point of view, it was widely demonstrated the economic advantage of repairing them [24, 78]; moreover, Inss Tek Inc. repaired a hot forging die (Fig. 10) and showed that the service life of the repaired die was 2.5 times higher with respect to the original die [88].

Bennett et al. [92] repaired an automotive steel die, illustrated in Fig. 11a, and showed that the repaired die, shown in Fig. 11b, was characterized by the same life as the original die life. On the contrary, the life of the die repaired using the traditional process varied between 12.5 and $29.2 \%$ with respect to the original die life. Moreover, the results of LCA showed that the LP-DED repair process has a lower environmental impact compared to traditional repair processes.

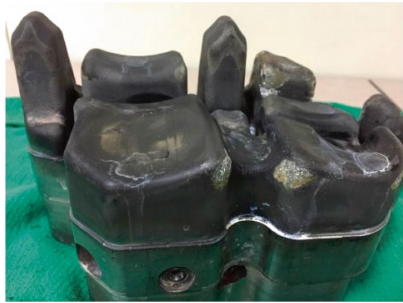

(a)

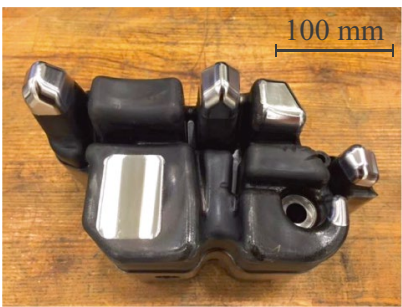

(b)
Fig. 11 a Damaged and b restored automotive die [92]

\subsection{LP-DED repair in other sectors}

The sustainability interest in the automotive industry is becoming more and more important $[93,94]$. Steel and grey cast iron are two of the most used materials in the production of car components [95]; hence, repairing these components could lead to an extension of end of life [94]. However, these materials are not easily repairable due to their tendency of crack formations. At this scope, studies were performed in order to optimize the process. For example, Bennett et al. [96] used LP-DED process to repair a grey cast iron diesel engine component with 316L stainless steel. Figure 12 depicts the component before and after the repair process. Cracks were reduced using a spiral deposition strategy. Moreover, before and after the deposition, preheating and postheating phases were used to control the heating and the cooling rate. The mechanical properties of components repaired using stainless steel were evaluated by Yu et al. [97]. They showed that comparing the traditional process with the LP-DED process, the HAZ was reduced from 2.2 to $0.1 \mathrm{~mm}$. Both the traditional and the LP-DED processes caused a reduction of the UTS of about $16 \%$ compared to the original part. However, it was observed that the repair process highly influenced the value of the elongation. Using the traditional process, the elongation decreased of about $20 \%$ compared to the undamaged part instead, and using LPDED process, it was observed that the elongation increased of about $60 \%$. Piasecki et al. [98] repaired a crankshaft pulley hub using Stellite 6. The repaired part was analysed using dye penetrant inspection. The result showed that no cracks, discontinuities, porosity, and other surface defects were present.

Due to the harsh environmental condition, components in the marine sector are usually subjected to corrosion, erosion, and oxidation [99] that reduce the operational cost [99, 100]. These components are usually repaired using welding techniques such as MIG and submerged arc; however, these techniques led to distortions, a large HAZ, and a poor repeatability [101]. On the other hand, Kampanis and Hauer [101] repaired a propeller shaft $11.2 \mathrm{~m}$ long and with a diameter

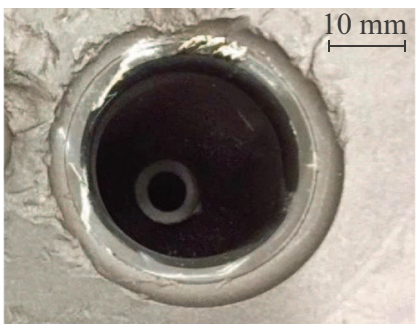

(a)

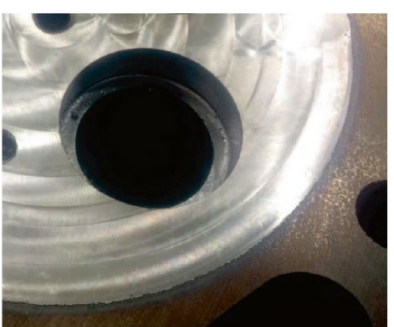

(b)
Fig. 12 Grey cast iron diesel engine $\mathbf{a}$ before and $\mathbf{b}$ after repairing operation [96] 
of $650 \mathrm{~mm}$ using the LP-DED process and showed that LPDED was a suitable process for a fast, efficient, and safe repair operation. For example, the in-service life of bulkheads was significantly affected by corrosion [102]. In naval ship and submarine sectors, HSLA-100 steel is the material widely used for bulkhead production [103] due to its high strength, good low-temperature impact, and good weldability [104]. Sun et al. [105] demonstrated that HSLA-100 steel plate could be successfully repaired using the LP-DED process. Repaired grooves were defect-free and a good metallurgical bonding was obtained. Results showed that conversely to cold spray, thermal spray, plasma spraying, and arc welding, using the LP-DED process, no cracks due to lower residual stress were observed. Moreover, the deformation of the repaired parts was very limited. Moreover, components in the marine sector are usually characterized by huge dimensions of over $400 \mathrm{~mm}$ [99-101]. Using conventional repair processes, such as TIG or PWAG, it is not possible to repair these components onboard and it is necessary to transport them to workshops or laboratories and this activity is time-consuming and expensive [99]. Hence, it is important to repair these components in situ without removing them from the case structure. KIMI successfully repaired marine pistons (Fig. 13) demonstrating the economic benefits of LP-DED process. Additionally, they demonstrated that the repaired components exhibited a higher hardness and corrosion resistance [24]. Hence, using the LP-DED process, the piston's service life was prolonged [106].

A marine diesel engine crankshaft was repaired by Koehler et al. [107]. Using the LP-DED process, a good metallurgical bonding between the deposited material and the base material was obtained. Figure 14 shows the top and the bottom views of the repaired crankshaft. The repaired width was of about $50 \mathrm{~mm}$ and during the repair operations, it was demonstrated that the functional aspects of crankshaft such as the oil bore were not altered or damaged. Later, Torims [108] used the LP-DED process as an in situ repair process for a marine

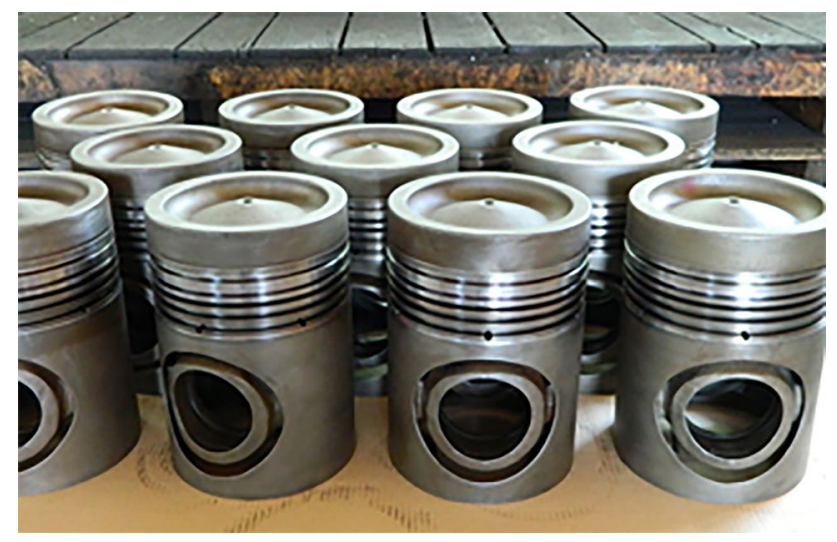

Fig. 13 MAN B\&W pistons repaired with the LP-DED process

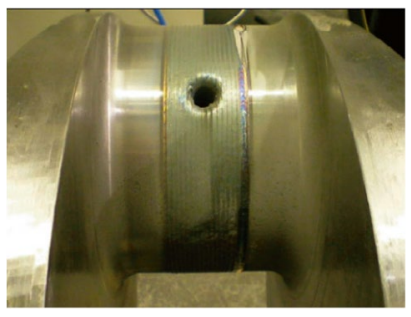

(a)

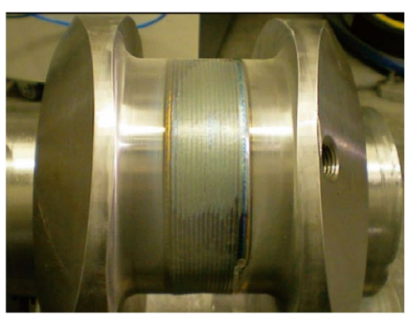

(b)
Fig. 14 Crankshaft repaired by LP-DED process [107]

crankshaft with a diameter of $450 \mathrm{~mm}$. The deposition head was placed onto the crankshaft journal grinding equipment. This solution allowed the repair process directly in the engine housing.

Another important sector in which the LP-DED repair process was successfully applied is the railway transport sector. In fact, among the other phenomena, rails were continuously damaged by the wear mechanism caused by the Rolling Contact Fatigue (RCF) [109-111]. In Europe, the cost related to damaged rail is of about $€ 2$ billion per year, and this cost includes inspection, train delay, replacement or repair of the damaged part, grinding, and loss of business [111]. The repairing process using wear-resistant material could reduce significantly the cost by increasing the in-service life of the rails [110,111]. Clare et al. [110] repaired a worn railway using different wear-resistant alloys, such as Ni alloy, Stellite 6, Hadfield steel, and Maraging steel. Their study aimed to evaluate the capability of the selected alloys to be used as a repairing material. Results showed that all the analysed alloys were suitable for the repair operation with a higher hardness value compared to the substrate material. Later, Lewis et al. [112] analysed the wear and the RCF of the same alloys. Both wear and RCF were improved using the wear resistance material in repairing operation. Using Stellite 6, the best results in terms of wear resistance were obtained. Instead, no significant variation of RCF life was observed by varying the material. In another study, Zhu et al. [113] repaired grade $\mathrm{C}$ railway wheels using three different stainless steel alloys that are $316 \mathrm{~L}, 410$, and 420 . The results showed that the repaired wheel disks were characterized by lower wear rates and RCF compared to the original wheel disks. On the contrary, the wear rates and the RCF of the repaired rail disks were higher with respect to the original disks. Sexton [114] repaired overhanging train carriage bearings by depositing on the bearing a hard resistant material. In his work, a Cobased alloy was used and the results showed that the life of the overhanging train carriage was extended. In addition, due to high cooling rates obtained in the process, a higher value of hardness was observed.

It is known that repairing internal defects, such as cracks, is more difficult with respect to the repair process on an 
external surface [49]. The effectiveness of the LP-DED process in repairing internal defects was demonstrated by Nowotny et al. [115]. In their work, erosion defects in large gun barrels were repaired using a novel internal diameter deposition head. Usually, the repair operation requires the machining of a groove in the damaged area. Onuike and Bandyopadhyay [116] repaired internal defects in Inconel 718 samples using different groove geometries. Results showed that better results were obtained by machining the damaged area with a trapezoidal shape with respect to a rectangular cross-section.

Pinkerton et al. [49] analysed the effect of the geometry of the groove on the deposition process. In particular, two different geometries were selected that are the square shape and the V shape. H-13 tool steel was used as a material. Results showed that vertical walls of the square-shaped groove were a problem; in fact, they shielded the powder flow and the laser beam, and as a consequence, a higher value of porosity was measured. Later, Graf et al. [117] deposited stainless steel and titanium powder in different groove shapes. In their study, the process parameters were varied and their influence on HAZ and microstructure were investigated. The results showed that if the groove was big enough for a proper powder stream, a repair operation without porosity was obtained. Moreover, the titanium powder was deposited without the use of additional inert gas using low heat input. The deposition strategy used in their study allowed obtaining constant offset between adjacent tracks and between consecutive layers and good side wall fusion as depicted in Fig. 15.

Oh et al. [118] studied the applicability of the LPDED process to repair damaged 316L L-PBF components with different groove depths. In their study, the mechanical properties were analysed using tensile tests, hardness measurements, and observing the fracture surface. Results showed that the LP-DED process could be used to repair L-PBF components; however, for large groove depth, cracks occurred due to the thermal residual stresses. The elongation and the strength of the repaired samples were respectively $5 \%$ and 3\% lower with respect to the original L-PBF components. On the other hand, no significant variation of microhardness was observed. Sun et al. [119] used the LP-DED process to repair $\mathrm{T}$ shape grooves on 316L stainless steel.
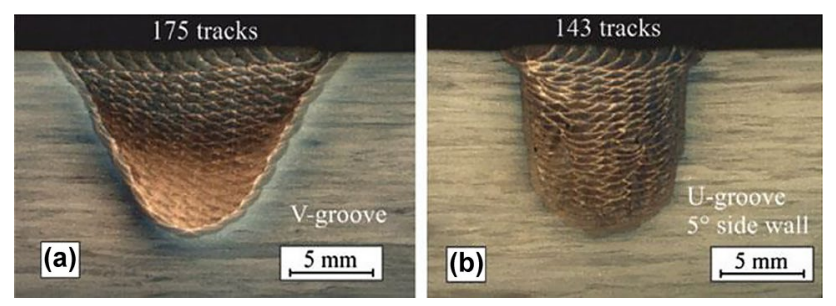

Fig. 15 Repair operation results in titanium components with different groove shapes [117]

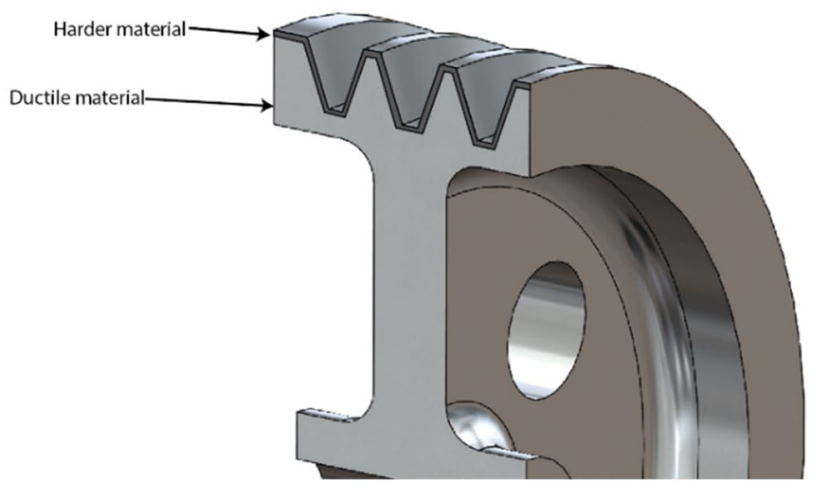

Fig. 16 Representation of the application of FGMs on a pulley

Results showed that the level of incident energy, that is, the ratio between the laser power and the travel speed, has a high influence on the quality of the repaired part. In particular, they showed that a too low value of incident energy caused pores; on the contrary, an excessive value of incident energy caused cracks due to thermal stresses.

\section{Functionally graded materials}

One of the main advantages of the LP-DED process is the possibility to produce components by varying the composition of the deposited material obtaining Functionally Graded Materials (FGMs) [33, 120]. With a local changing of the materials that constituted the part, it is possible to optimize the functionality of the part. Hence, the properties of FGMs components are non-uniform but they change within the components [121]. For example, considering a pulley, it is more advisable to use a harden and wear-resistant material near the hub and the rim and a more ductile material in the core (Fig. 16) [122]. The mechanical properties of the interface zone between the two materials are in the middle between the properties of pure materials as summarized in Table 3.

Several conventional techniques were widely used in the industry that allowed obtaining FGMS components such as Physical Vapour Deposition (PVD), Chemical Vapour Deposition (CVD), Powder Metallurgy (PM), and Centrifugal Method (CM) [27, 28, 130, 131]. However, using the LPDED process, higher production, lower energy consumption, and maximum material utilization, in addition to the possibility to produce complex shapes, with respect to conventional processes were obtained [132]. Moreover, the LP-DED process allows to modifying the design process introducing the chemical composition as a design parameter [133].

In the following paragraphs, the most relevant findings obtained both in the industrial and the academic fields are presented, referring to the macrosector of application, that 
Table 3 Mechanical properties of some FGMs produced by LP-DED

\begin{tabular}{|c|c|c|c|c|}
\hline Material & $\begin{array}{l}\text { Elongation, } \\
\varepsilon(\%)\end{array}$ & $\begin{array}{l}\text { Yield } \\
\text { strength, YS } \\
\text { (MPa) }\end{array}$ & $\begin{array}{l}\text { Ultimate } \\
\text { tensile } \\
\text { strength, } \\
\text { UTS (MPa) }\end{array}$ & Ref \\
\hline $316 \mathrm{~L}$ & 34 & 530 & 660 & [123] \\
\hline $\mathrm{P} 21$ & 19 & 980 & 1050 & \\
\hline 316L/P21 & 10.3 & 970 & 1360 & \\
\hline $316 \mathrm{~L}$ & 71 & 296 & 562 & [124] \\
\hline IN625 & 62 & 443 & 815 & \\
\hline 316L/IN625 & 43 & 406 & 606 & \\
\hline $304 \mathrm{~L}$ & $\mathrm{n} / \mathrm{a}$ & $\mathrm{n} / \mathrm{a}$ & $\mathrm{n} / \mathrm{a}$ & [125] \\
\hline $\mathrm{Cu}$ & 58 & 95 & 187 & \\
\hline $304 \mathrm{~L} / \mathrm{Cu}$ & 25 & 123 & 250 & \\
\hline SS420 & 6.8 & $\mathrm{n} / \mathrm{a}$ & 1925 & [126] \\
\hline IN718 & 15.6 & $\mathrm{n} / \mathrm{a}$ & 1071 & \\
\hline SS420/IN718 & 13.5 & $\mathrm{n} / \mathrm{a}$ & 910 & \\
\hline IN625 & 41 & 671 & 925 & [127] \\
\hline $\mathrm{Cu}$ & $\mathrm{n} / \mathrm{a}$ & $\mathrm{n} / \mathrm{a}$ & $\mathrm{n} / \mathrm{a}$ & \\
\hline IN625/Cu & 23 & 153 & 215 & \\
\hline IN718 & 32.5 & 285 & 540 & [128] \\
\hline Stellite 6 & 18.1 & 353 & 676 & \\
\hline IN718/Stellite 6 & 35.1 & 330 & 625 & \\
\hline Ti6Al4V & $\mathrm{n} / \mathrm{a}$ & 1072 & 1169 & [129] \\
\hline $\mathrm{TiC}$ & $\mathrm{n} / \mathrm{a}$ & $\mathrm{n} / \mathrm{a}$ & $\mathrm{n} / \mathrm{a}$ & \\
\hline Ti6Al4V & $\mathrm{n} / \mathrm{a}$ & 985 & 1196 & \\
\hline
\end{tabular}

$n / a$ not applicable

are aerospace, tooling, and all the other sectors not included in the first two.

\subsection{LP-DED FGM parts in aerospace}

The aerospace sector was the first sector in which FGMs were applied [59]. FGM components include rocket engine components, the spacecraft truss structure, and the heat exchange panels [59]. However, the produced parts are characterized by high stress concentration and delaminations may occur [134]. Hence, several feasibility studies were performed in order to optimize the combination of materials with different characteristics considering both the process parameters and the composition. In addition, also the geometry and the dimension of the join influence the mechanical performance [131].

Titanium alloys are widely used in the aerospace sector due to their high corrosion resistance, high strength to weight ratio, low density, and high strength at high temperature [135, 136]; however, they suffer from poor wear resistance and low hardness [137]. For this reason, to overcome this problem, different FGM materials were studied. Among the others, TiC was one of the most studied materials in order to produce titanium FGM components, due to its metallurgical compatibility with titanium alloys, its low density, and its high values of hardness and Young's modulus [138-140].

Obielodan and Stucker [129] analysed the effect of different transitional joints on tensile and flexural strengths of FGM Ti6Al4V/TiC samples. Results showed that the joint types did not affect the flexural strength however highly influenced the tensile strength. Mahamood and Akinlabi [141] produced defect-free FGM Ti6Al4V/TiC samples. They showed that the microhardness and the wear resistance were improved optimizing the process parameters for each material composition. The optimization of process parameters was obtained using a model previously developed [142]. Zhang et al. [140] studied the effect of process parameters and TiC composition on microstructure and mechanical properties of FGM Ti6Al4V/TiC samples. Results showed that increasing the energy, both the primary dendrite arm spacing (PDAS) and the secondary dendrite arm spacing (SDAS) increased. The hardness value was mainly influenced by the TiC content; on the contrary, the specific energy did not influence the hardness value. They showed that $\mathrm{TiC}$ content influenced the mechanical properties. In particular, the Young modulus increased and the ultimate tensile stress decreased with increasing the TiC content.

Moreover, it should be noted that different aerospace components, such as telescopes and high-precision optical mirror substrates [143, 144], are subjected to large temperature variations that could induce thermal shock and dimensional deformations [143]. This can be reduced by using materials characterized by a low thermal expansion coefficient [143]. For example, Bobbio et al. [144] produced FGMs of Ti6Al4V to Invar. However, the samples were characterized by macroscopic defects such as material overflow and cracks. The cracks were developed due to the residual stresses and the mismatch in Young modulus.

Inconel is another material successfully used in aerospace applications due to the high-temperature corrosion resistance, fatigue, and creep resistance [145]. To improve the thermal conductivity of Inconel 718, Onuike et al. [146] produced In718/GRCop-84 FGM. GRCop-84 is a copper-based alloy used in the main combustion chamber and nozzle liners [147]. Two approaches were used that are the direct deposition of GRCop-84 on In718 and the gradual variation of GRCop-84 alloy during the deposition. The results showed that using the gradual variation, a more uniform interface was obtained and an increase of thermal conductivity of about $300 \%$ was obtained compared to IN718. However, in order to produce defect-free samples, the specific energy should be increased of about $270 \%$ due to the high reflectivity of GRcop- 84 .

\subsection{LP-DED FGM in tooling industry}

One of the first industrial applications of FGM materials concerned surface coating and was obtained by Heyden 
Laser Services. This is a company based in Massachusetts and its applications are focused on wear-resistant coatings in tools and die, in nuclear and in power generation industries [32]. The first step was to compare the capability of the LP-DED process with the conventional processes. Using the LP-DED process for the deposition of tungsten carbide in a nickel matrix, they obtained a better metallurgical bond with respect to that achieved using conventional processes such as thermal spray or plasma transfer process [32]. Then, the LP-DED process was compared with TIG welding by Thivillon et al. [148], analysing the coating quality of Co-based Stellite and $\mathrm{Ni}$ superalloy Inconel 625 . The coating quality was evaluated by means of different characteristics such as microstructure, hardness, and dilution. The results showed that using the LP-DED process, higher hardness and finer grain were obtained. Moreover, the metallurgical bond obtained using TIG welding showed lots of irregularities; in contrast, the metallurgical bond obtained using LP-DED appears excellent (Fig. 17).

The hardness is one of the most important factors affecting the die life; in fact, the die life increases with the hardness value $[149,150]$. H-13 tool steel is one of the most used materials in the moulding sector [151] due to its high hardenability and high thermal fatigue resistance $[42,152]$. Although it has benefits, at elevated temperature, the hardness value decreases sharply [152]. Hence, studies were performed in order to deposit hard material on the $\mathrm{H}-13$ matrix. TiC was widely used in order to increase mould wear and corrosion resistance $[153,154]$ at elevated temperatures. Jiang et al. [155] used $\mathrm{Ni} / \mathrm{Cr}$ alloy to improve the adhesion between H-13 and TiC. Zhang et al. [156] optimized the process parameters varying the ratio of premixed $\mathrm{Ti}$ and TiC powder. They showed that hardness and wear resistance increase with the $\mathrm{TiC}$ content; in contrast, the ductility decreases with the TiC content. Chen et al. [157] depositing CoMoCr alloy on $718 \mathrm{H}$ steel showed that the mould microhardness has increased twice with respect to the initial configuration due to the formation of carbide and martensite hard phases.

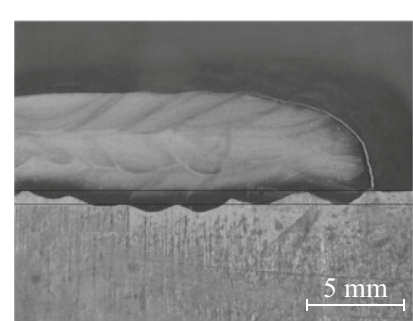

(a)

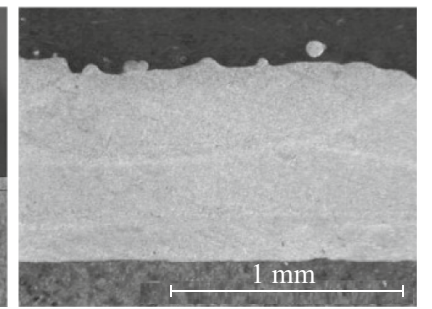

(b)
Fig. 17 Comparison of Stellite 6 coating using a TIG and b DMD process [148]
In addition to the mechanical characteristics, FGM materials were successfully applied in order to optimize the energy consumption, the environmental impact, and the material usage of moulds and dies [40, 42, 88]. In fact, another disadvantage of $\mathrm{H}-13$ tool steel is the low thermal conductivity [158] that causes a longer time cycle. In order to optimize energy consumption, environmental impact, and material usage, and, furthermore, to minimize the cycle time, highly conductive materials have been used as a volumetric heat sink. These materials include Ampcoloy 940 [159], copper alloy [40, 79, 159], and tool steel [160]. Morrow et al. [79] showed that depositing H-13 tool steel onto a copper substrate, as represented in Fig. 18, the injection moulding time cycle can be reduced of about $25 \%$ compared to a conventional tool steel mould. However, when depositing copper on a steel substrate, some difficulties can arise due to the heterogeneous properties of the two materials [161]. For example, Noecker and DuPont [162] during the deposition of pure copper on AISI H-13 steel showed the presence of three cracking susceptibility levels that depends on the $\mathrm{Cu}$ concentration. These cracks were attributed to the large solidification temperature range, to the formation of undesired phase, and to the differences in the thermal expansion coefficient. This behaviour was confirmed by Beal et al. [163] and they found that the cracks could be reduced by preheating the powder particles. They also showed that samples with densities over than $90 \%$ could be produced by optimizing the deposition strategy and that the laser parameters affect the spatter and the balling effect and consequently the product quality.

Ahn and Kim [159] produced a thermal management mould, depicted in Fig. 19, using three different materials: Ampcoloy 940 used as base part, P21 tool steel used as a moulding part, and Monel 400 used in the mid-layer in order to reduce the thermal stresses in the joined regions. Results showed that the cycle time and the cooling time

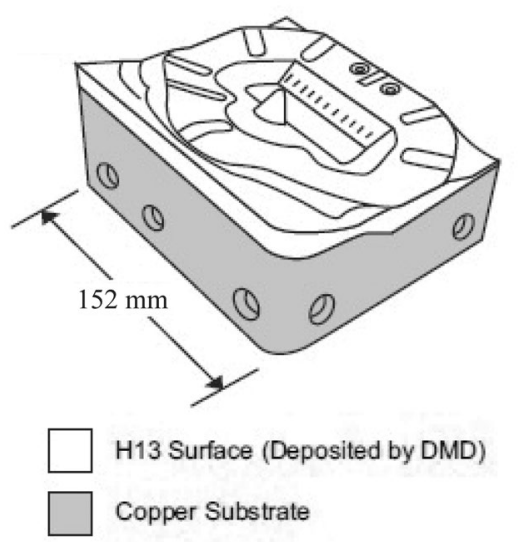

Fig. 18 Functionally graded tool steel-copper mould [79] 


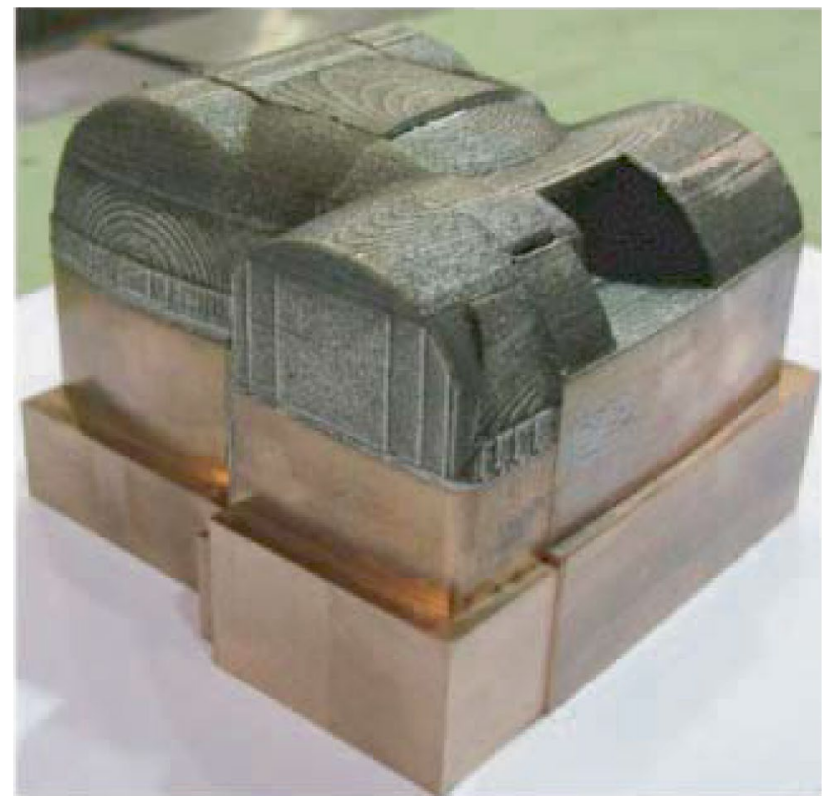

Fig. 19 Functionally graded thermal management mould [159]

using the FGM mould were reduced of about $30 \%$ and $80 \%$ respectively.

Fessler et al. [164] produced FGM sample from 100\% stainless steel to $100 \%$ Invar. This FGM material was selected due to its excellent properties. In fact, stainless steel was used for high corrosion resistance $[165,166]$ while Invar exhibits a very low coefficient of thermal expansion and hence it was used for reducing the distortion due to the residual stress [167]. This FGM material was applied by ALCOA in order to produce an advanced injection mould. The mould was characterized by a copper core to minimize the cycle time, by an Invar body to reduce the deformations due to thermal stresses, and by an external surface of stainless steel in order to prevent the corrosion [164].

\subsection{Other applications of LP-DED FGM}

The production of FGMs using steel and Inconel were successfully used in order to improve the wear and corrosion resistance in the automotive sector [121, 133, 168]. FGM components in automotive include valve stems, pistons, driveshaft, and shock absorbers [121, 133]. Inconel alloys were successfully applied due to their good mechanical and corrosion resistance at elevated temperatures $[169,170]$. Carroll et al. [120] successfully used the LP-DED process to produce a sample with a graded structure from 304L stainless steel to 625 Inconel alloy (Fig. 20). The FGM component was obtained by varying the mass amount of IN625 powder deposited during the process. Results obtained from microscopy show a gradual modification of microstructure without sharp differences. For a composition of about 82

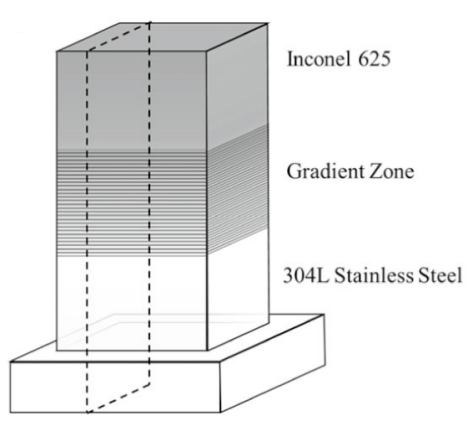

(a)

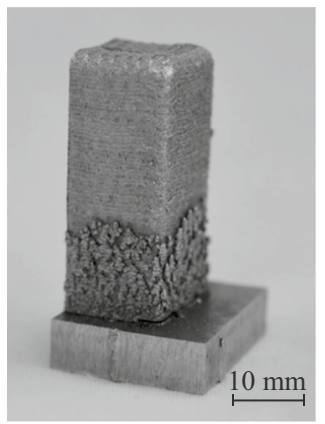

(b)
Fig. 20 a Theoretical and b DED produced functionally graded material sample [120]

wt\% SS304L, particles with a dimension of about few microns of secondary phase were observed. These secondphase particles caused cracks with a dimension of about $100 \mu \mathrm{m}$ during the deposition process. Savitha et al. [171] deposited FGMs of 316L stainless steel and Inconel 615 in order to establish the capability of the LP-DED process to produce FGMs. Results showed that using the LP-DED process, crack-free samples have been produced; however, some porosities and unmelted particles were observed. Later, Zhang et al. [124] analysed the microstructure of 316L/IN615 FGM samples. The microstructure of the samples showed that a sharp variation was obtained for pure 316L and Inconel 615 samples; instead, for gradient samples, the microstructure changed progressively. Mirzana et al. [172] studied the phase distribution and the formation of an interface region during the fabrication of FGM SS316 and IN625 disk. The disk consists of an inner region of ss 316 and an outer region of IN625. The microstructure result showed a uniform variation of the properties without the formation of cracks in the interface region. The Vickers hardness values measured in the SS316 in the interface and in the IN625 regions were 200, 291, and 345, respectively. Liu et al. [173] used IN625 as a buffer material between cast iron and SS420. Using IN625, they avoided the problems related to high hardenability and cold cracking of SS420 [174]. Chen et al. [175] showed that when the IN615 content exceeds the $80 \%$, the white second phase occurred in the dendrite boundary and an increase of hardness and wear resistance was observed. However, the formation of the second phase was the main factor that caused the reduction of tensile properties.

Wu et al. [176] deposited two FGM SS316L/IN718 samples using two different deposition patterns, with the composition gradually modified during the process. The first sample grows along the building direction, and the second one was produced in the $x y$-plane. Results showed that the first sample was characterized by a columnar to equiaxed transition with the minimum value of microhardness measured in 
Table 4 Comparison of mechanical properties of samples produced by conventional and LP-DED process

\begin{tabular}{llllll}
\hline Material & Production method & $\begin{array}{l}\text { Elongation, } \\
\boldsymbol{\varepsilon}(\%)\end{array}$ & $\begin{array}{l}\text { Yield strength, } \\
\text { YS (MPa) }\end{array}$ & $\begin{array}{l}\text { Ultimate tensile } \\
\text { strength, UTS (MPa) }\end{array}$ & Ref \\
\hline $316 \mathrm{~L}$ & Forging & 40 & 170 & 450 & {$[186]$} \\
& LP-DED AB & 33.9 & 530 & 660 & {$[17]$} \\
\multirow{2}{*}{ IN625 } & Annealed bar & 30 & 403 & 841 & {$[187]$} \\
& LP-DED & 69 & 487 & 815 & {$[53]$} \\
IN718 & Casting & 26.2 & 557 & 895 & {$[188]$} \\
& LP-DED AB & 36.3 & 582 & 838 & {$[188]$} \\
Ti6A14V & Casting & 13.5 & 865 & 980 & {$[26]$} \\
& LP-DED AB & 6.4 & 881 & 902 & {$[135]$} \\
\hline
\end{tabular}

correspondence of $50 \%$ v/o IN718, while in the second sample, the microhardness grows linearly with IN718 content. Shah et al. [177] studied the effect of process parameters on the microstructure, the mechanical properties, and the wear resistance of 316L/IN718 FGM samples. Results showed that the secondary arm spacing is strongly influenced by laser power and powder feed rate. The tensile strength and the hardness of the samples were inversely proportional to the laser power and increases with powder feed rate.

Several parts of the human body are classifiable as FGMS $[121,130]$; for this reason, several efforts were performed in order to optimize biocompatible implants [121]. Balla et al. [178] used the LP-DED process to create an FGM material in order to improve the osseointegration properties. In their work, the tantalum was selected as a coating material due to the high corrosion resistance, its bioactive capability, and the capacity to bond to the bone. Producing tantalum parts using conventional production technologies involves high manufacturing costs and, moreover, is not possible to produce modular all-tantalum implants [178]. Using the LPDED process, the authors successfully deposited a tantalum coating on titanium parts and they showed the capability to create modular all-tantalum implants. Another material widely used in the biomedical sector is the $\mathrm{Co}-\mathrm{Cr}-\mathrm{Mo}$ alloy [179]; however, an abrupt variation between $\mathrm{Co}-\mathrm{Cr}-\mathrm{Mo}$ and Ti6Al4V resulted in severe cracks due to the poor metallurgical compatibility. Optimizing LP-DED process parameters, Bandyopadhyay et al. [180] obtained a crack-free deposit of Co-Cr-Mo on Ti6Al4V alloy with a good reproducibility. Krishna et al. [181] studied the biocompatibility of Ti6Al4V/ Co-Cr-Mo FGM material by varying the Co-Cr-Mo concentration on the top surface. Results showed that the living cells, and hence the biocompatibility, after 14 days of culture decreased with increasing the $\mathrm{Co}-\mathrm{Cr}-\mathrm{Mo}$ alloy concentration. However, the optimal combination in terms of wear resistance and biocompatibility was obtained for $50 \% \mathrm{Co}-\mathrm{Cr}-\mathrm{Mo}$ alloy concentration. Janaki Ram et al. [182] during the deposition of FGM pure Ti/TiC samples showed that defect-free coating could be produced. The coatings consist of a mix of irregular partially melted $\mathrm{TiC}$ particles and fine resolidified
TiC particles. The amount of these particles and the hardness increased with increasing the TiC content.

\section{Production}

Production of near net shape components without the use of tools and moulds is one of the main benefits of AM processes [183]. This allows material saving and lead time reduction [184, 185]. In most cases, the production applications of LP-DED refer to the production of large components and to the production using high melting point alloys. In addition, it should be noted that the production using the LPDED process is on average ten times faster with respect to the L-PBF process [5]. Moreover, as summarized in Table 4, the mechanical characteristics of the sample produced by LP-DED are comparable with the properties obtained using the conventional processes. The examples of components produced by the LP-DED process are presented in this section highlighting the sector in which they were applied, which are aerospace sector, tooling sector, and all the other sectors.

\subsection{Production of aerospace parts by LP-DED}

One of the most important sectors in which the LP-DED process has been strongly used for production is the aerospace sector. The main reason that drives the use of the LP-DED process in this sector is the possibility to produce components with larger dimensions with respect to those produced using the L-PBF process [5, 189]. For example, in 2003, the Northwest Polytechnic University produced a central wing spar for Comac C313 passenger aeroplane (Fig. 21). The central wing spar is $5 \mathrm{~m}$ long and the mechanical properties were comparable with those obtained in the forging process [190]. The production was performed using an LP-DED cell characterized by a working volume of $5 \times 2.5 \times 0.6 \mathrm{~m}^{3}$ with an accuracy of $\pm 1 \mathrm{~mm}[65]$.

DMG Mori produced a stainless steel turbine housing using LASERTEC 65 3D hybrid machine (Fig. 22). The 


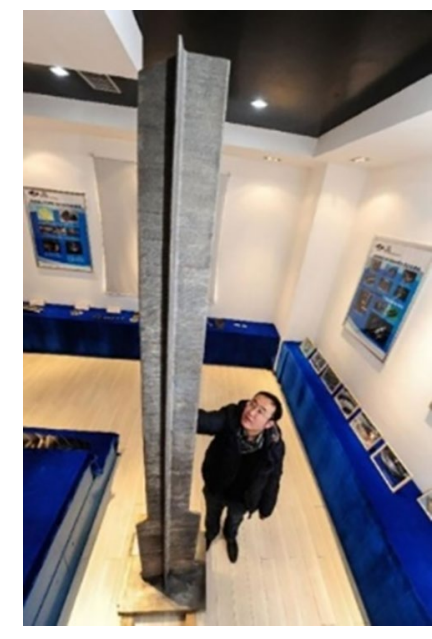

Fig. 21 A 5-m-long titanium wing spar for Comac C919 [190]

turbine housing was characterized by a diameter of $180 \mathrm{~mm}$ and a height of $150 \mathrm{~mm}$. The time required for the production of this component was about 230 min [191]. Another example of the application of the LP-DED process was presented by TWI [192]. Using a five-axis LP-DED machine, an Inconel 718 helicopter engine combustion chamber was successfully produced (Fig. 23). The dimensions of the produced chamber were $300 \mathrm{~mm}$ in diameter and $90 \mathrm{~mm}$ in height. The as-built component showed an average tolerance with respect to the CAD geometry of about $0.25 \mathrm{~mm}$. Moreover, an accuracy of about $0.09 \mathrm{~mm}$ on the dimension of the produced thin wall was obtained. Additionally, TWI showed that the built time was reduced from 2 months for the conventional manufacturing process to $7.2 \mathrm{~h}$ for the production using the LP-DED process.

In addition to the production of large components, different studies revealed the LP-DED process allows a short time delivery of components compared to the conventional manufacturing processes. Hedges and Calder [48] showed that thanks to its flexibility, the LP-DED process can be used to manage the fast design modification without the need for retooling. Figure 24 showed a housing used in defence applications produced by LP-DED. With the conventional manufacturing system, the time required for the production of the housing is of about 6 months; instead, using the LP-DED process, part was manufactured within 3 days [48].

Another study made by the National Center for Manufacturing Science (NCMS) showed that the LP-DED process reduced the time required to produce moulds of about $40 \%$ [40]. Another application of LP-DED in the aerospace sector was performed in 2004 by Bell Helicopter. The requirement of high material integrity and fast delivery led to the use of the LP-DED process. LENS 850-R system was used to produce a titanium $1 / 6$ scale mixing nozzle (Fig. 25) for a gas turbine of a military helicopter. The time required for the production was reduced from 9 weeks using the conventional casting process to 3 weeks [48].

An increase of building rate value could be obtained by increasing the deposition speed. However, it is not possible to increase the speed very much due to the limited acceleration of the motor of the deposition head [196]. Moreover, as the deposition speed increases, the deposited material exhibited convex shapes that deviate much from the nominal dimension. Hence, Ma et al. [196] in order to produce large components with high deposition speed optimized the deposition strategy in order to minimize the geometrical deviation. This optimization was performed on a bracket that was designed likewise of pylon ribs of wing components in aircraft applications. In their experiment, a variational orientation raster scanning (VORS) deposition strategy was developed. The results showed that using the developed deposition strategy, the deviations were reduced from 4 to $1 \mathrm{~mm}$. Figure 26 depicts the bracket produced in the experimental validation of the deposition strategy.

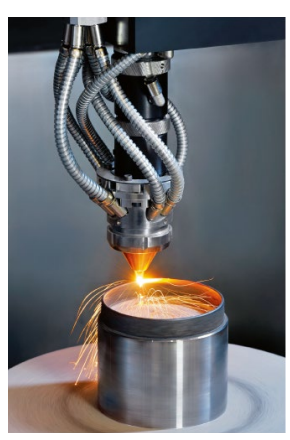

(a)

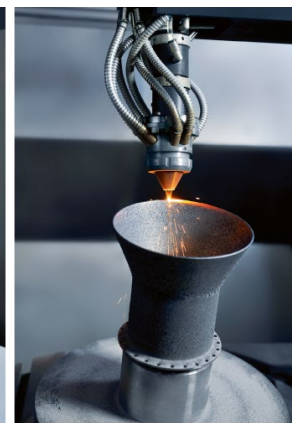

(b)

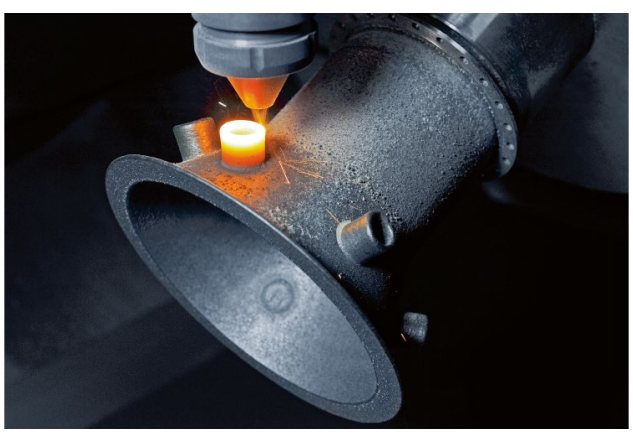

(c)

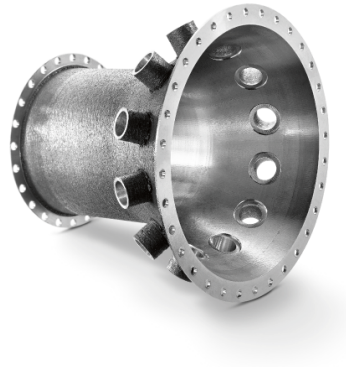

(d)
Fig. 22 Production of a stainless steel turbine housing (dimensions $\Phi 180 \mathrm{~mm} \times 150 \mathrm{~mm}$ ): a realization of the main cylinder, $\mathbf{b}$ production of the inclined surface by rotating the building table, $\mathbf{c}$ produc- tion of the 12 lateral connections, and $\mathbf{d}$ component after finishing operations (courtesy of DMG Mori) [193] 
Fig. 23 Realization of an IN718 helicopter engine combustion chamber with dimensions of $300 \mathrm{~mm}$ (courtesy of TWI) [194]

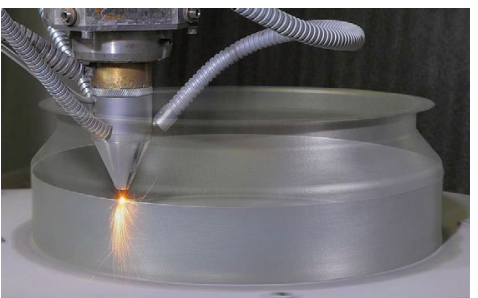

(a)

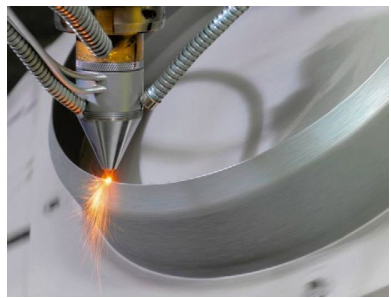

(b)

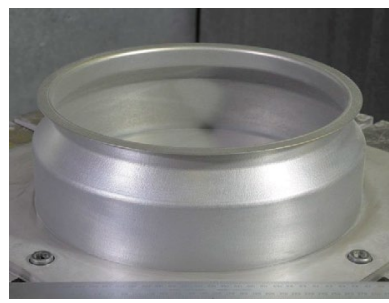

(c)
In addition to time, production using the LP-DED process can bring benefits to costs. For example, Hedges and Calder [48] showed that the manufacturing costs associated with the production of the housing depicted in Fig. 24 were reduced by $65 \%$.

\subsection{Production of tools and moulds by LP-DED}

The problem associated with the production of dies and moulds using the conventional production processes was related to the lead time required to manufacture them, that in some cases can be up to a year [197]. To solve this issue, the LP-DED process was successfully applied in different studies in order to reduce manufacturing times. Studies performed by Morrow et al. [79] and by POM Group Inc. [88] showed that the lead times using the LP-DED process were reduced by approximately $70 \%$ with respect to those obtained using conventional processes.

Another important aspect of the LP-DED process is the possibility to deposit directly onto an existing surface [22, 30, 36]. This capability was used by Morrow et al. [79] for remanufacturing a stamping die used by a US truck manufacturer. The remanufacturing operations consist of a modification of the geometry of the die and the relocation of the manufacturer logo. Results showed that the energy consumption of remanufacturing operations was less than half of the energy consumption required to manufacture a new die. The authors estimated that this energy saving led to a cost saving of about 250,000 over the life cycle of the analysed die.

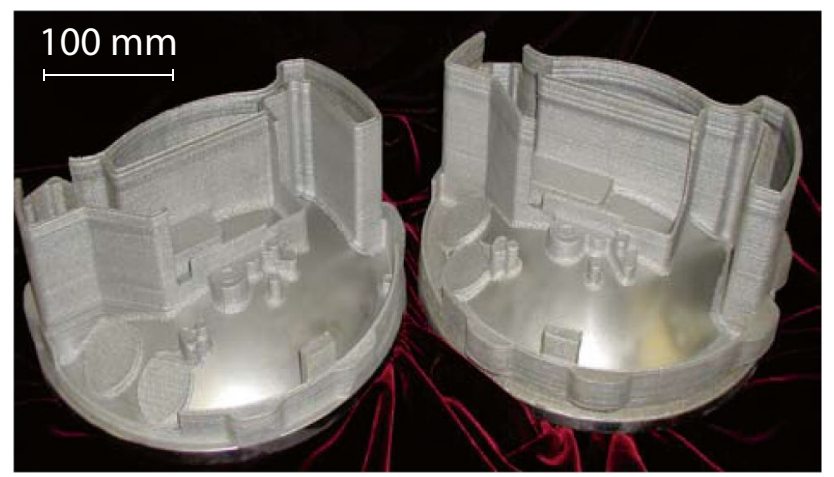

Fig. 24 Produced 316L housing for defence application (courtesy of Optomec $($ ) [195]
In addition, the application of AM processes in the manufacturing industry leads to the possibility to produce moulds with conformal cooling channels [42]. In order to verify the capability of the LP-DED process to produce conformal cooling channels and to evaluate the resulting benefits, J.S. Die \& Mold in collaboration with POM Group Inc. [198] produced a mould used for the production of wheel type components [88]. Results showed that the mould and the conformal cooling channels were successfully produced. Moreover, the use of conformal cooling channels led to a reduction of the moulding cycle time of $20-50 \%$ which is reflected in an economical benefit $[42,88]$.

\subsection{Production by LP-DED in other sectors}

Different applications can also be found in the biomedical sector. The major issue of metal implants used in the medical field is the mismatch between the mechanical characteristics of the metal part and the bone that could lead to fractures and other problems [199, 200]. Hence, some studies were focused on reducing this mismatch. For example, Dinda et al. [201] used the LP-DED process to produce a Ti6Al4V scaffold for patient-specific bone tissue engineering (Fig. 27). The process was performed in a controlled chamber using a mix of argon

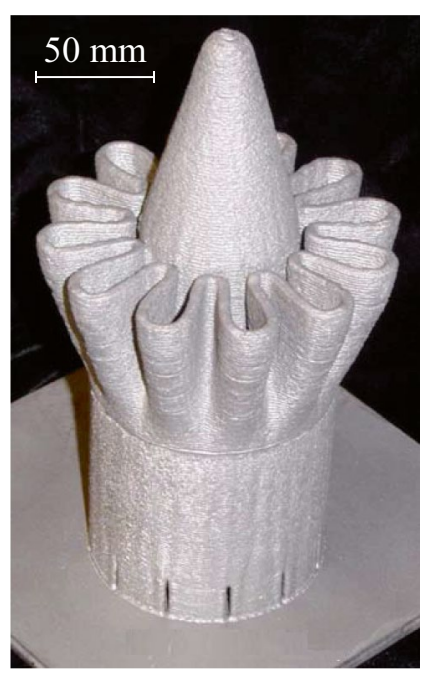

Fig. 25 Ti64 1/16 scale model of a mixing nozzle for a gas turbine produced by Bell Helicopter (courtesy of Optomec $®$ ) [195] 

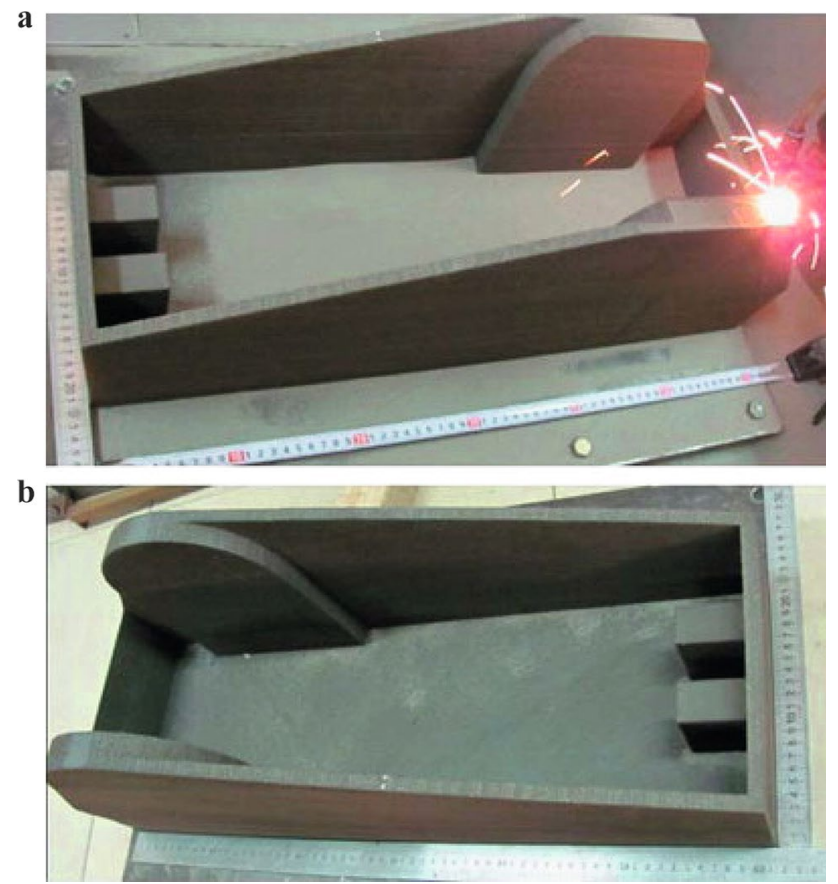

Fig. 26 316L large-scale bracket produced by laser powder directed energy deposition process: a during the deposition process and $\mathbf{b}$ the final result [196]

and helium; in this way, the problem related to oxidation was reduced. The average surface roughness of the as-built scaffold was $25 \mu \mathrm{m}$. After sandblasting operation, the surface roughness was reduced to $12 \mu \mathrm{m}$ achieving the recommended criteria for bone tissue engineering. The as-built part was characterized by

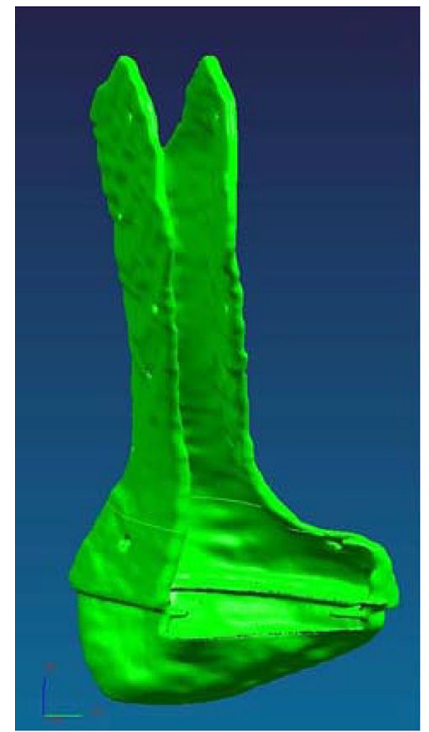

(a) (b)

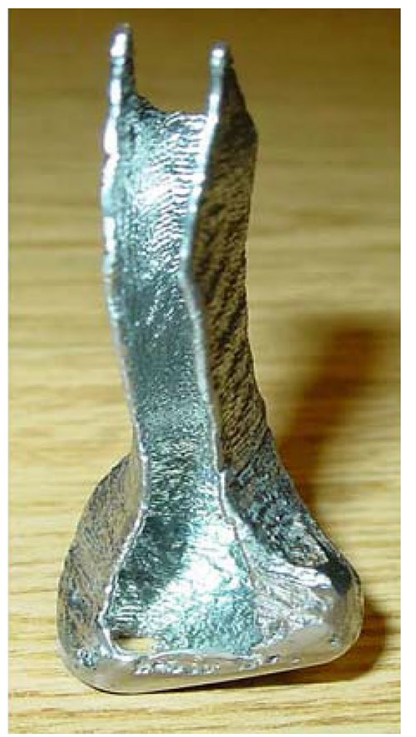

Fig. 27 a STL file and b Ti6Al4V scaffold produced by DMD process [201]

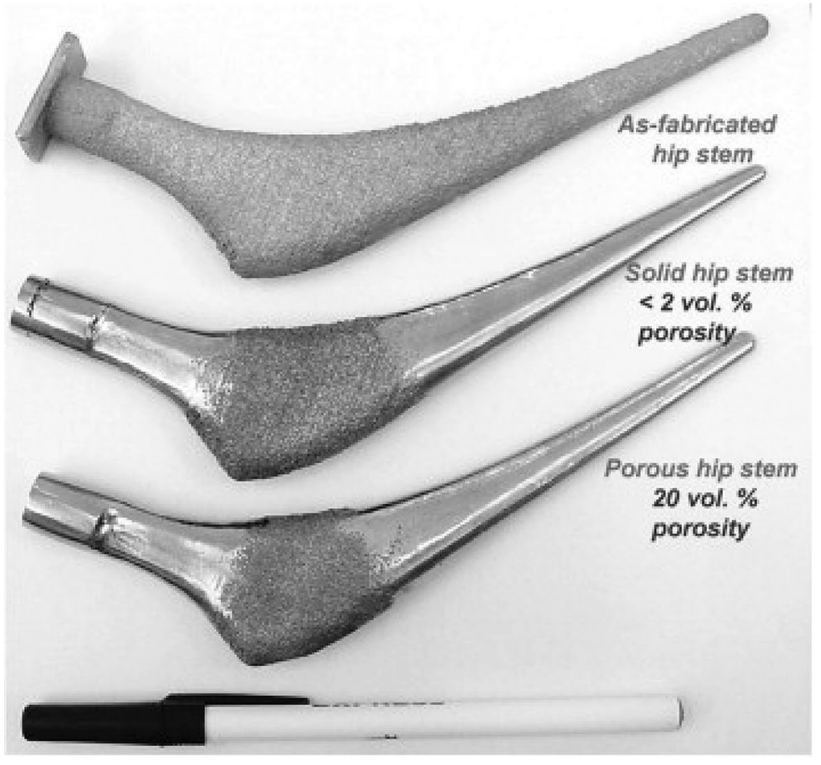

Fig. 28 Functional hip stems with different levels of porosity obtained by varying process parameters in the LP-DED process [202]

very high tensile and yield strengths, $1163 \mathrm{MPa}$ and $1105 \mathrm{MPa}$, respectively; however, the ductility was below the limit defined by ASTM F136-79. As a consequence, a heat treatment was performed in order to increase the value of the ductility. Their work demonstrates that LP-DED is a suitable process for the production of hard tissue biomaterials.

Krishna et al. [202] proposed a method that allowed producing functional hip stems using the LP-DED process (Fig. 28). In their study, the process parameters and the design approach were varied in order to obtain an internal porosity. This induced internal porosity which allowed to reduce the bulk density of the component and a reduction of the difference between the stiffness of the bone and the stiffness of the implanted material was obtained. Results showed that the bulk density was reduced from 4.5 to $3.6 \mathrm{~g} /$ $\mathrm{cm}^{3}$ and that the LP-DED process can be successfully used to produce custom implants with personalized properties depending on the patient's need.

Moreover, Palčič et al. [200] showed that the use of the LP-DED process could lead to a less complicated operation procedure. They produced a hollow, thin-walled intramedullary nail (IM nail) used for the fixation of the radius bone head (Fig. 29). The selected material for the experiment was titanium alloy Ti6Al4V due to its biocompatibility, resistance to corrosion, and osteointegration. In his work, the component produced using LP-DED process was compared with the component produced using conventional technologies (turning and drilling). The results showed that the component produced by LP-DED process was lighter, due to the hollow structure, and it was also characterized by an easier use due to the absence of attendance instruments [200]. 


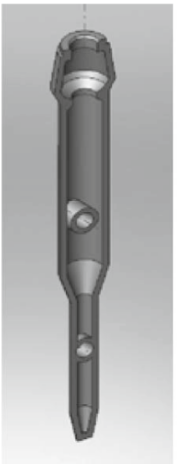

(a)

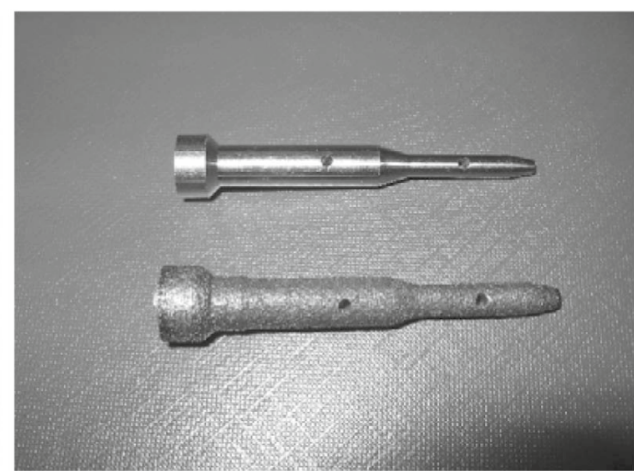

(b)
Fig. 29 a CAD cross-section and $\mathbf{b}$ Ti6Al4V prototypes of an IM nail before and after finishing operations [200]

Further sectors in which the LP-DED process was applied are the automotive, tool production, military, and the space sector, highlighting the benefits in terms of cost and time that could be obtained by using the LP-DED process. For example, driveshaft spiders and suspension mountain brackets for the Red Bull Racing car were successfully produced by Optomec using the LP-DED process. The produced components are illustrated in Fig. 30. Using The LP-DED process, a significant reduction of time of about $50 \%$ and of the cost was obtained. Moreover, a reduction of waste material of about $92 \%$ for suspension mounting bracket and of about 97\% for drive shaft spider was achieved.

In Advanced Robotics Mechatronics System (ARMS) project, the benefits of producing an integrated boom/housing of a space robot manipulator using the LP-DED process were evaluated [203]. The produced part is illustrated in Fig. 31. Results showed that for complex parts, the LP-DED process is economically convenient. On the contrary, for

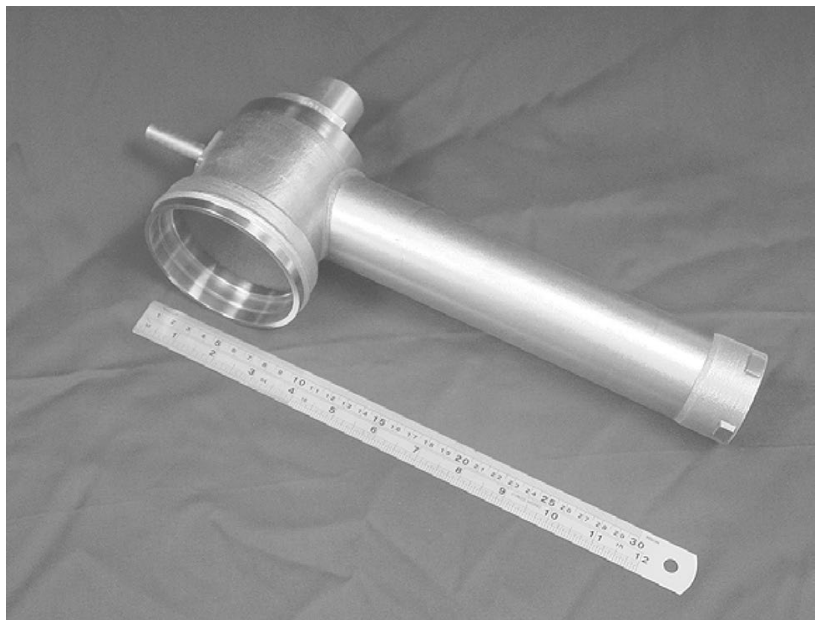

Fig. 31 LP-DED integrated boom/housing [203]

small parts with simple geometry, economic benefits could be obtained by using conventional manufacturing processes. Moreover, the potentiality of the LP-DED process in particular for remote autonomous operations was demonstrated, considering also the economic advantages that derive from integrating different components into one final part.

Xue et al. [204] used the LP-DED process to produce rotatory cutting dies of CPM-9 V tool steel (Fig. 32). They successfully produced several rotatory dies and the benefits of the LP-DED process with respect to the conventional manufacturing process were proved. In particular, they demonstrated that the die produced by the LP-DED process cut over than $180,000 \mathrm{~m}$ of labels without the necessity of a reshapening. Using the LP-DED process, the production time was reduced by one third compared to conventional production processes. Furthermore, the material cost was
Fig. 30 a Ti64 suspension mounting bracket and b Ti64 gearbox spider produced by LENS process saving above $90 \%$ material losses (courtesy of Optomec $($ ) [195]

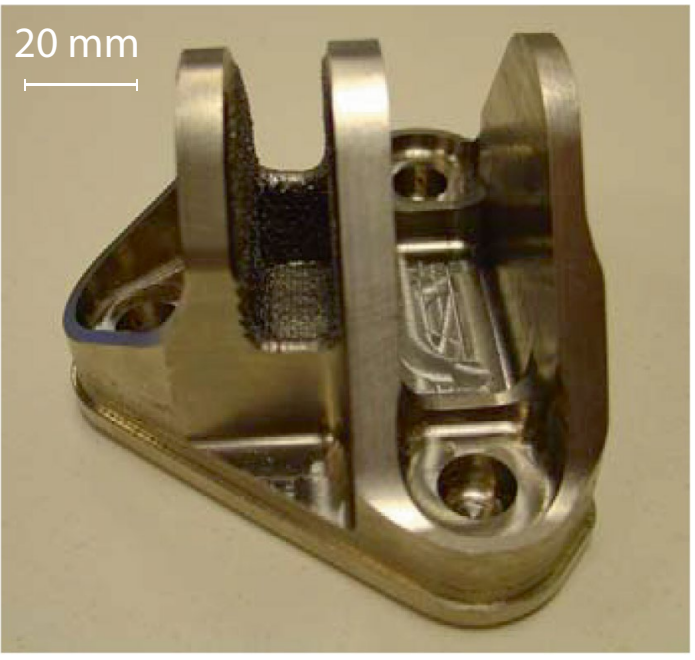

(a)

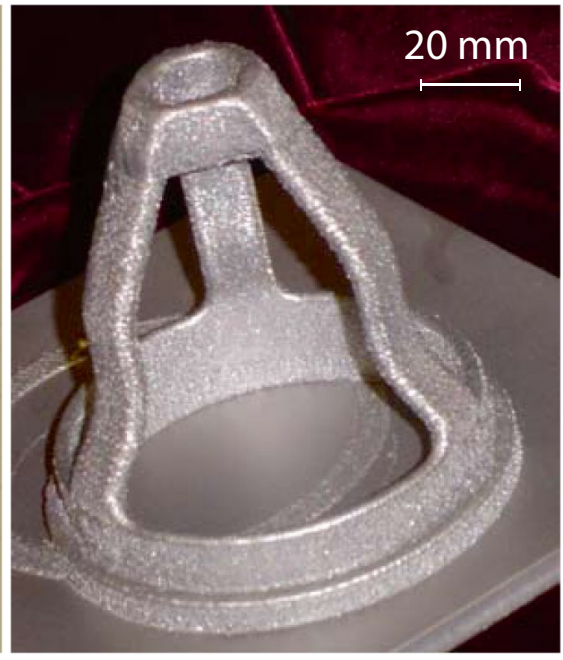

(b) 


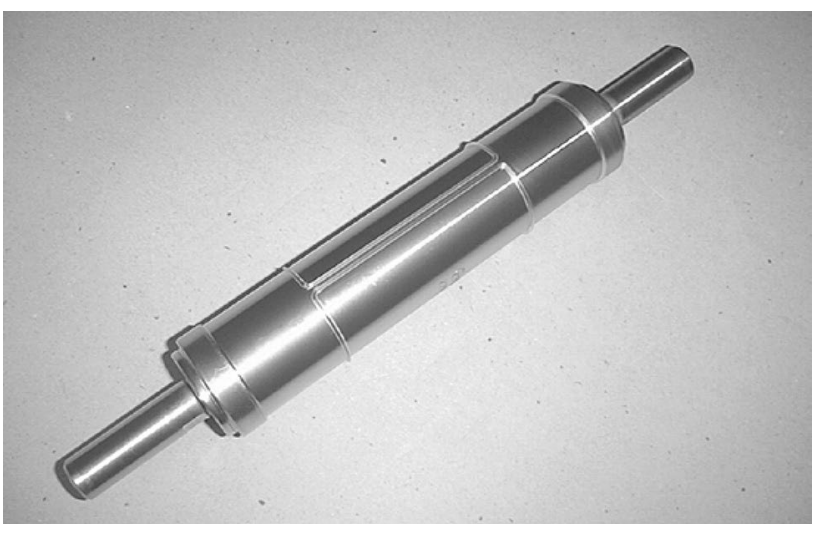

Fig. 32 LP-DED CPM-9 V rotatory cutting die after finishing operation [205]

reduced of about $50 \%$ and the die life increased by approximately $100 \%$.

Finally, the LP-DED process was also successfully applied in sonar application for the production of the folder shell projector (FPS) []. This component is characterized by a complex thin-wall structure with inner sharp corners that are non-realizable using the conventional manufacturing processes [205]. NCR-IMI in collaboration with Defense Research \& Development Canada (DRDC) demonstrated that the LP-DED process could be used to produce the FPS without cracks or defects [205].

\section{Conclusion and future outlook}

The purpose of the current review is to provide a summary of the current industrial application of the LP-DED process. The main advantages of the LP-DED process with respect to other AM processes are the possibility to produce large components, the possibility to deposit the material onto an existing surface, and the possibility to change the deposited material directly during the manufacturing process.

It was observed that the main application refers to repair operations of high-value components characterized by complex shapes, such as turbine blades. The reasons that encourage the use of the LP-DED process with respect to other repairing processes, such as TIG or plasma transferred arc welding, are the lower heat input, the lower warpage and distortions, and the higher precision. Moreover, using the LP-DED process, significant cost and time saving could be obtained. Further research works are needed for optimizing the process parameters in order to increase the surface quality that is at the current state one of the major issues of the LP-DED process. In addition, to improve the process, obtaining a higher repeatability is also necessary to understand the effect of the shape and the dimensions of the substrate, which in the case of repair operations coincides with the damaged part.

Thanks to the combined possibility to deposit onto an existing surface and to use different materials during the manufacturing process, the LP-DED process is widely used to produce designed materials. This capability was applied in different sectors to improve mechanical properties such as the wear and the corrosion resistance, the hardness, and thermal properties such as the thermal conductivity in moulds in order to improve the thermal exchange. At this stage, the application of the FGM is mainly limited to feasibility cases that studied the interface region due to the complex phenomena that occur by melting two dissimilar materials. The main problem is that the process parameters should be selected for each couple of used materials. Simulation models could help to overcome this problem by defining and limiting the process parameter window and thus limiting the experimental tests required to optimize the process parameters. From the literature review, it emerges that up to now, the LP-DED process is used for the production of a limited number of parts that were characterized by relatively simple geometry and by high dimensions. This is related to the fact that the LP-DED process is not able to manage components characterized by overhanging features. The integration between tilted substrates and the motion of the deposition head allows overcoming to this limit. However, it is necessary to analyse the effect of an inclined substrate on the characteristics of the deposition parameters, such as the powder flow and the power absorption.

Data availability Not applicable.

Code availability Not applicable.

\section{Declarations}

Ethics approval Not applicable.

Consent to participate Not applicable.

Consent for publication Not applicable.

Conflict of interest The authors declare no competing interests.

Open Access This article is licensed under a Creative Commons Attribution 4.0 International License, which permits use, sharing, adaptation, distribution and reproduction in any medium or format, as long as you give appropriate credit to the original author(s) and the source, provide a link to the Creative Commons licence, and indicate if changes were made. The images or other third party material in this article are included in the article's Creative Commons licence, unless indicated otherwise in a credit line to the material. If material is not included in the article's Creative Commons licence and your intended use is not permitted by statutory regulation or exceeds the permitted use, you will 
need to obtain permission directly from the copyright holder. To view a copy of this licence, visit http://creativecommons.org/licenses/by/4.0/.

\section{References}

1. Böckin D, Tillman A-M (2019) Environmental assessment of additive manufacturing in the automotive industry. J Clean Prod 226:977-987. https://doi.org/10.1016/j.jclepro.2019.04.086

2. Leal R, Barreiros FM, Alves L, Romeiro F, Vasco JC, Santos M, Marto C (2017) Additive manufacturing tooling for the automotive industry. Int J Adv Manuf Technol 92(5-8):1671-1676. https://doi.org/10.1007/s00170-017-0239-8

3. Javaid M, Haleem A (2018) Additive manufacturing applications in orthopaedics: a review. J Clin Orthop Trauma 9(3):202-206. https://doi.org/10.1016/j.jcot.2018.04.008

4. Javaid M, Haleem A (2019) Current status and applications of additive manufacturing in dentistry: a literature-based review. J Oral Biol Craniofac Res 9(3):179-185. https://doi.org/10.1016/j. jobcr.2019.04.004

5. Liu R, Wang Z, Sparks T, Liou F, Newkirk J (2017) Aerospace applications of laser additive manufacturing. In: Laser additive manufacturing. Woodhead Publishing pp. 351-371

6. Lyons B (2014) Additive manufacturing in aerospace: examples and research outlook. The Bridge 44(3)

7. Uriondo A, Esperon-Miguez M, Perinpanayagam S (2015) The present and future of additive manufacturing in the aerospace sector: a review of important aspects. Proceedings of the Institution of Mechanical Engineers Part G- J Aerosp Eng 229(11):2132-2147. https://doi.org/10.1177/0954410014568797

8. Petrovic V, Gonzalez JVH, Ferrando OJ, Gordillo JD, Puchades JRB, Grinan LP (2011) Additive layered manufacturing: sectors of industrial application shown through case studies. Int J Prod Res 49(4):1061-1079. https://doi.org/10. 1080/00207540903479786

9. Atzeni E, Salmi A (2012) Economics of additive manufacturing for end-usable metal parts. Int J Adv Manuf Technol 62(912):1147-1155. https://doi.org/10.1007/s00170-011-3878-1

10. Weller C, Kleer R, Piller FT (2015) Economic implications of 3D printing: market structure models in light of additive manufacturing revisited. Int J Prod Econ 164:43-56. https://doi.org/ 10.1016/j.ijpe.2015.02.020

11. Jiang R, Kleer R, Piller FT (2017) Predicting the future of additive manufacturing: a Delphi study on economic and societal implications of 3D printing for 2030. Technol Forecast Soc Chang 117:84-97. https://doi.org/10.1016/j.techfore.2017.01.006

12. ISO / ASTM52900-15 (2015) Standard terminology for additive manufacturing-general principles-terminology. ASTM International, West Conshohocken, PA

13. Frazier WE (2014) Metal additive manufacturing: a review. J Mater Eng Perform 23(6):1917-1928. https://doi.org/10.1007/ s11665-014-0958-Z

14. Piscopo G, Salmi A, Atzeni E (2021) Influence of high-productivity process parameters on the surface quality and residual stress state of AISI 316L components produced by directed energy deposition. J Mater Eng Perform 30(9):6691-6702. https://doi.org/10.1007/ s11665-021-05954-3

15. Thompson SM, Bian L, Shamsaei N, Yadollahi A (2015) An overview of direct laser deposition for additive manufacturing. Part I: transport phenomena, modeling and diagnostics. Addit Manuf 8:36-62. https://doi.org/10.1016/j.addma.2015. 07.001

16. Aversa A, Piscopo G, Salmi A, Lombardi M (2020) Effect of heat treatments on residual stress and properties of AISI $316 \mathrm{~L}$ steel processed by directed energy deposition. J Mater Eng Perform. https://doi.org/10.1007/s11665-020-05061-9

17. Saboori A, Piscopo G, Lai M, Salmi A, Biamino S (2020) An investigation on the effect of deposition pattern on the microstructure, mechanical properties and residual stress of $316 \mathrm{~L}$ produced by directed energy deposition. Mater Sci Eng A 780. https://doi.org/10.1016/j.msea.2020.139179

18. Cherdo L (2019) The best metal 3D printers in 2019. Accessed 19/06 2019 https://www.aniwaa.com/best-of/3d-printers/bestmetal-3d-printer/

19. Wohlers T, Campbell RI (2017) Wohlers report 2017: 3D printing and additive manufacturing state of the industry: annual worldwide progress report. Wohlers Associates, Incorporated

20. Caiazzo F, Alfieri V (2019) Simulation of laser-assisted directed energy deposition of aluminum powder: prediction of geometry and temperature evolution. Materials (Basel) 12(13):2100. https://doi.org/10.3390/ma12132100

21. Caiazzo F, Alfieri V, Argenio P, Sergi V (2017) Additive manufacturing by means of laser-aided directed metal deposition of 2024 aluminium powder: investigation and optimization. Adv Mech Eng 9(8):1687814017714982. https://doi.org/10.1177/ 1687814017714982

22. Vilar R (2014) Laser powder deposition. Comprehensive materials processing. Elsevier, Oxford, pp 163-216

23. Dass A, Moridi A (2019) State of the art in directed energy deposition: from additive manufacturing to materials design. Coatings 9(7). https://doi.org/10.3390/coatings9070418

24. Saboori A, Aversa A, Marchese G, Biamino S, Lombardi M, Fino P (2019) Application of directed energy deposition-based additive manufacturing in repair. Appl Sci Basel 9(16):3316. https:// doi.org/10.3390/app9163316

25. Tang ZJ, Liu WW, Wang YW, Saleheen KM, Liu ZC, Peng ST, Zhang Z, Zhang HC (2020) A review on in situ monitoring technology for directed energy deposition of metals. Int J Adv Manuf Technol 108(11-12):3437-3463. https://doi.org/10.1007/ s00170-020-05569-3

26. Liu SY, Shin YC (2019) Additive manufacturing of Ti6Al4V alloy: a review. Mater Des 164. https://doi.org/10.1016/j.matdes. 2018.107552

27. Naebe M, Shirvanimoghaddam K (2016) Functionally graded materials: a review of fabrication and properties. Appl Mater Today 5:223-245. https://doi.org/10.1016/j.apmt.2016.10.001

28. Bohidar SK, Sharma R, Mishra PR (2014) Functionally graded materials: a critical review. Int J Res Sci Eng 1(4):289-301

29. Pratheesh Kumar S, Elangovan S, Mohanraj R, Ramakrishna JR (2021) A review on properties of Inconel 625 and Inconel 718 fabricated using direct energy deposition. Materials Today: Proceedings 46:7892-7906. https://doi.org/10.1016/j.matpr.2021.02. 566

30. Gibson I, Rosen D, Stucker B (2015) Directed energy deposition processes. Addit Manuf pp 245-268

31. ASTM F3187-16 (2016) Standard guide for directed energy deposition of metals. ASTM International, West Conshohocken, PA

32. Pinkerton A (2010) Laser direct metal deposition: theory and applications in manufacturing and maintenance. In: Advances in laser materials processing. Elsevier pp 461-491

33. Lewis GK, Schlienger E (2000) Practical considerations and capabilities for laser assisted direct metal deposition. Mater Des 21(4):417-423. https://doi.org/10.1016/S0261-3069(99)00078-3

34. Ziętala M, Durejko T, Polański M, Kunce I, Płociński T, Zieliński W, Łazińska M, Stępniowski W, Czujko T, Kurzydłowski KJ (2016) The microstructure, mechanical properties and corrosion resistance of $316 \mathrm{~L}$ stainless steel fabricated using laser engineered net shaping. Mater Sci Eng, A 677:1-10

35. Toyserkani E, Khajepour A, Corbin SF (2004) Laser cladding. CRC Press 
36. Piscopo G, Atzeni E, Salmi A (2019) A hybrid modeling of the physics-driven evolution of material addition and track generation in laser powder directed energy deposition. Materials (Basel) 12(17):2819. https://doi.org/10.3390/ma12172819

37. Lewis GK, Nemec R, Milewski J, Thoma DJ, Cremers D (1994) Barbe M (1994) Directed light fabrication. Int Cong Appl Lasers Electro-Opt 1:17-26

38. Mah R (1997) Directed light fabrication. Adv Mater Processes 151(3):31-33

39. Griffith ML, Keicher DL, Romero J, Atwood C, Harwell L, Greene D, Smugeresky J (1996) Laser engineered net shaping (LENS) for the fabrication of metallic components, Sandia National Labs., Albuquerque, NM (United States)

40. Mazumder J, Dutta D, Kikuchi N, Ghosh A (2000) Closed loop direct metal deposition: art to part. Opt Lasers Eng 34(4-6):397414. https://doi.org/10.1016/S0143-8166(00)00072-5

41. Mazumder J, Schifferer A, Choi J (1999) Direct materials deposition: designed macro and microstructure. Mater Res Innov 3(3):118-131

42. Mazumder J, Choi J, Nagarathnam K, Koch J, Hetzner D (1997) The direct metal deposition of H13 tool steel for 3-D components. J Miner Met Mater Soc 49(5):55-60. https://doi.org/10. 1007/Bf02914687

43. Dutta B, Palaniswamy S, Choi J, Song L, Mazumder J (2011) Direct metal deposition. Adv Mater Process 33

44. Milewski JO, Thoma DJ, Fonseca JC, Lewis GK (1998) Development of a near net shape processing method for rhenium using directed light fabrication. Mater Manuf Processes 13(5):719730. https://doi.org/10.1080/10426919808935294

45. Milewski JO, Lewis GK, Thoma DJ, Keel GI, Nemec RB, Reinert RA (1998) Directed light fabrication of a solid metal hemisphere using 5-axis powder deposition. J Mater Process Technol 75(13):165-172. https://doi.org/10.1016/S0924-0136(97)00321-X

46. Milewski JO, Dickerson PG, Nemec RB, Lewis GK, Fonseca JC (1999) Application of a manufacturing model for the optimization of additive processing of Inconel alloy 690. J Mater Process Technol 91(1-3):18-28. https://doi.org/10.1016/S0924-0136(98)00412-9

47. Boehm V (2016) Hybrid manufacturing of turbine components: laser metal deposition (LMD) and adaptive repair for higher precision and shorter production time. Laser Tech J 13(2):44-47

48. Hedges M, Calder N (2006) Near net shape rapid manufacture \& repair by LENS, Cost Effective Manufacture via Net-Shape Processing, Meeting Proceedings RTO-MP-AVT-139. Paper 13

49. Pinkerton AJ, Wang W, Li L (2008) Component repair using laser direct metal deposition. Proceedings of the Institution of Mechanical Engineers Part B- J Eng Manuf 222(7):827-836. https://doi.org/10.1243/09544054jem1008

50. Zhang JW, Yu LM, Liu YC, Ma ZQ, Li HJ, Liu CX, Wu JF, Ma JG, Li ZL (2018) Analysis of the effect of tungsten inert gas welding sequences on residual stress and distortion of CFETR vacuum vessel using finite element simulations. Metals 8(11):912. https://doi.org/10.3390/met8110912

51. Su C, Chou C, Wu B, Lih W (1997) Plasma transferred arc repair welding of the nickel-base superalloy IN-738LC. J Mater Eng Perform 6(5):619-627

52. Bi GJ, Gasser A (2011) Restoration of nickel-base turbine blade knife-edges with controlled laser aided additive manufacturing, Lasers in Manufacturing: Proceedings of the Sixth International Wlt Conference on Lasers in Manufacturing 12(12):402-409. https://doi.org/10.1016/j.phpro.2011.03.051

53. Wilson JM, Piya C, Shin YC, Zhao F, Ramani K (2014) Remanufacturing of turbine blades by laser direct deposition with its energy and environmental impact analysis. J Clean Prod 80:170 178. https://doi.org/10.1016/j.jclepro.2014.05.084

54. Gasser A, Backes G, Kelbassa I, Weisheit A, Wissenbach K (2010) Laser additive manufacturing: laser metal deposition
(LMD) and selective laser melting (SLM) in turbo-engine applications. Laser Tech J 7(2):58-63

55. Song LJ, Bagavath-Singh V, Dutta B, Mazumder J (2012) Control of melt pool temperature and deposition height during direct metal deposition process. Int J Adv Manuf Technol 58(1-4):247256. https://doi.org/10.1007/s00170-011-3395-2

56. Petrat T, Graf B, Gumenyuk A, Rethmeier M (2016) Laser metal deposition as repair technology for a gas turbine burner made of Inconel 718, Laser Assisted Net Shape Engineering 9. International Conference on Photonic Technologies Proceedings of the Lane 83:761-768. https://doi.org/10.1016/j.phpro.2016.08.078

57. Selcuk C (2013) 13-joining processes for powder metallurgy parts. In: Advances in powder metallurgy. Woodhead Publishing pp 380-398

58. Nowotny S, Scharek S, Beyer E, Richter KH (2007) Laser beam build-up welding: precision in repair, surface cladding, and direct 3D metal deposition. J Therm Spray Technol 16(3):344-348. https://doi.org/10.1007/s11666-007-9028-5

59. Mahamood RM (2018) Areas of application of laser metal deposition process - part repair and remanufacturing. Laser metal deposition process of metals, alloys, and composite materials. Springer International Publishing, Cham, pp 143-164

60. Simoneau L, Bois-Brochu A, Blais C (2020) Tensile properties of built and rebuilt/repaired specimens of 316L stainless steel using directed energy deposition. J Mater Eng Perform 29(9):61396146. https://doi.org/10.1007/s11665-020-05087-z

61. Rauch M, Hascoët J-Y, Mallaiah M (2020) Repairing Ti-6Al$4 \mathrm{~V}$ aeronautical components with DED additive manufacturing. MATEC Web of Conferences 321:03017

62. Ruiz-Salas E, Gonzalez-Barrio H, Calleja-Ochoa A, Ukar-Arrien E, Lamikiz-Mentxaka A (2018) Turbo engine components repair methodology by laser material deposition. Dyna 93(6):643-649. https://doi.org/10.6036/8838

63. Yilmaz O, Gindy N, Gao J (2010) A repair and overhaul methodology for aeroengine components. Robot Comput Integr Manuf 26(2):190-201. https://doi.org/10.1016/j.rcim.2009.07.001

64. Dey NK (2014) Additive manufacturing laser deposition of Ti-6Al-4V for aerospace repair application

65. Kumar LJ, Krishnadas Nair CG (2017) Current trends of additive manufacturing in the aerospace industry. In: Advances in 3D printing \& additive manufacturing technologies. Springer Singapore, Singapore, pp 39-54

66. Abdulrahman KO, Akinlabi ET, Mahamood RM (2018) Laser metal deposition technique: sustainability and environmental impact. Procedia Manuf 21:109-116

67. Optomec (2014) Blisk Repair Solution. Accessed 3 December 2021 https://www.optomec.com/wp-content/uploads/2014/04/ Optomec_LENS_Blisk_Repair_Datasheet.pdf

68. Optomec (2016) Turbine Bladed Disk (Blisk) Repair. Accessed 05/11 $2021 \mathrm{https} / / /$ optomec.com/turbine-bladed-disk-blisk-repair/

69. Commission E (2010) Accessed 02/12/2010 https://cordis. europa.eu/article/id/89781-sustainable-costeffective-aircraftengine-production

70. Kelbassa I, Albus P, Dietrich J (2008) Wilkes J (2008) Manufacture and repair of aero engine components using laser technology. Pacific International Conference on Applications of Lasers and Optics 1:208-213

71. Kumar LJ, Nair GK (2017) Laser metal deposition repair applications for Ti-6Al-4V alloy

72. Liu Q, Janardhana M, Hinton B, Brandt M, Sharp K (2011) Laser cladding as a potential repair technology for damaged aircraft components. Int J Struct Integr

73. Saboori A, Piscopo G, Lai M, Salmi A, Biamino S (2020) An investigation on the effect of deposition pattern on the microstructure, mechanical properties and residual stress of $316 \mathrm{~L}$ 
produced by directed energy deposition. Mater Sci Eng A Struct Mater Prop Microstruct Process 780

74. Zhang XC, Li W, Chen XY, Cui WY, Liou F (2018) Evaluation of component repair using direct metal deposition from scanned data. Int J Adv Manuf Technol 95(9-12):3335-3348. https://doi. org/10.1007/s00170-017-1455-y

75. Kistler NA, Corbin DJ, Nassar AR, Reutzel EW, Beese AM (2019) Effect of processing conditions on the microstructure, porosity, and mechanical properties of Ti-6Al-4V repair fabricated by directed energy deposition. J Mater Process Technol 264:172-181. https://doi.org/10.1016/j.jmatprotec.2018.08.041

76. Qi H, Azer M, Singh P (2010) Adaptive toolpath deposition method for laser net shape manufacturing and repair of turbine compressor airfoils. Int J Adv Manuf Technol 48(1-4):121-131. https://doi.org/10.1007/s00170-009-2265-7

77. Jones JB, McNutt P, Tosi R, Perry C, Wimpenny DI (2012) Remanufacture of turbine blades by laser cladding, machining and in-process scanning in a single machine

78. Jhavar S, Paul CP, Jain NK (2013) Causes of failure and repairing options for dies and molds: a review. Eng Fail Anal 34:519-535. https://doi.org/10.1016/j.engfailanal.2013.09.006

79. Morrow WR, Qi H, Kim I, Mazumder J, Skerlos SJ (2007) Environmental aspects of laser-based and conventional tool and die manufacturing. J Clean Prod 15(10):932-943. https://doi.org/10. 1016/j.jclepro.2005.11.030

80. Jhavar S, Paul CP, Jain NK (2016) Micro-plasma transferred arc additive manufacturing for die and mold surface remanufacturing. Jom 68(7):1801-1809. https://doi.org/10.1007/ s11837-016-1932-z

81. Preciado WT, Bohorquez CEN (2006) Repair welding of polymer injection molds manufactured in AISI P20 and VP50IM steels. J Mater Process Technol 179(1-3):244-250. https://doi.org/10. 1016/j.jmatprotec.2006.03.101

82. Borrego LP, Pires JTB, Costa JM, Ferreira JM (2009) Mould steels repaired by laser welding. Eng Fail Anal 16(2):596-607. https://doi.org/10.1016/j.engfailanal.2008.02.010

83. Kattire P, Paul S, Singh R, Yan WY (2015) Experimental characterization of laser cladding of CPM 9V on $\mathrm{H} 13$ tool steel for die repair applications. J Manuf Process 20:492-499. https://doi. org/10.1016/j.jmapro.2015.06.018

84. Leunda J, Soriano C, Sanz C, Navas VG (2011) Laser cladding of vanadium-carbide tool steels for die repair. Lasers in Manufacturing 2011: Proceedings of the Sixth International Wlt Conference on Lasers in Manufacturing 12(12):345-352. https://doi.org/10. 1016/j.phpro.2011.03.044

85. Nikam SH, Jain NK (2017) Laser-based repair of damaged dies, molds, and gears. Springer. J Adv Manuf Technol pp 137-159

86. Lestan Z, Milfelner M, Balic J, Brezocnik M, Karabegovic I (2013) Laser deposition of Metco 15E, Colmony 88 and VIM CRU 20 powders on cast iron and low carbon steel. Int J Adv Manuf Technol 66(9-12):2023-2028. https://doi.org/10.1007/ s00170-012-4478-4

87. Ren L, Padathu AP, Ruan J, Sparks T, Liou FW (2008) Three dimensional die repair using a hybrid manufacturing system. Austin, TX

88. Ahn DG (2011) Applications of laser assisted metal rapid tooling process to manufacture of molding \& forming tools-state of the art. Int J Precis Eng Manuf 12(5):925-938. https://doi.org/10. 1007/s12541-011-0125-5

89. Leino M, Pekkarinen J, Soukka R (2016) The role of laser additive manufacturing methods of metals in repair, refurbishment and remanufacturing —enabling circular economy. Laser Assisted Net Shape Engineering 9 International Conference on Photonic Technologies Proceedings of the Lane 83:752-760. https://doi. org/10.1016/j.phpro.2016.08.077
90. Ahn DG (2016) Direct metal additive manufacturing processes and their sustainable applications for green technology: a review. Int J Pr Eng Man-GT 3(4):381-395. https://doi.org/10.1007/ s40684-016-0048-9

91. ISO Standard 14040 Standard I ISO Environmental managementlife cycle assessment: principles and framework

92. Bennett J, Garcia D, Kendrick M, Hartman T, Hyatt G, Ehmann K, You FQ, Cao J (2019) Repairing automotive dies with directed energy deposition: industrial application and life cycle analysis. J Manuf Sci Eng ASME 141(2). https://doi.org/10. $1115 / 1.4042078$

93. Goepp V, Zwolinski P, Caillaud E (2014) Design process and data models to support the design of sustainable remanufactured products. Comput Ind 65(3):480-490. https://doi.org/10.1016/j. compind.2014.02.002

94. Yusoh SSM, Abd Wahab D, Azman AH (2020) Analysis of automotive component design for reparation using additive manufacturing technology. Int J Integr Eng 12(5):20-26. https://doi.org/ 10.30880/ijie.2020.12.05.003

95. Fentahun MA, Savaş M (2018) Materials used in automotive manufacture and material selection using ashby charts. Int J Mater Eng 8:40-54

96. Bennett J, Dudas R, Cao J, Ehmann K, Hyatt G (2016) Control of heating and cooling for direct laser deposition repair of cast iron components. 2016 International Symposium on Flexible Automation (ISFA) pp. 229-236

97. Yu JH, Choi YS, Shim DS, Park SH (2018) Repairing casting part using laser assisted additive metal-layer deposition and its mechanical properties. Opt Laser Technol 106:87-93. https://doi. org/10.1016/j.optlastec.2018.04.007

98. Piasecki A, Bartkowski D, Młynarczyk A, Dudziak A, Gościański M, Kasprowiak M (2013) Laser cladding of Stellite 6 on low carbon steel for repairing components in automotive applications using disk laser. Arch Mech Technol Autom 33(2):25-34

99. Torims T, Bruckner F, Ratkus A, Fokejevs A, Logins A (2014) The application of laser cladding to marine crankshaft journal repair and renovation. Syst Eng 45837:V001T13A001

100. Morales Casas A, Torims T, Gutierrez Rubert SC (2019) Additive manufacturing as a technique for in situ repair and renovation of marine crankshaft journals. Key Eng Mater 799:263-269

101. Kampanis N, Hauer I (2010) Propeller shaft repair for a large ferry with the aid of laser cladding technique

102. Yamamoto N, Ikegami K (1998) A study on the degradation of coating and corrosion of ship's hull based on the probabilistic approach. J Offshore Mech Arct Eng Trans ASME 120(3):121128. https://doi.org/10.1115/1.2829532

103. Czyryca EJ, Link RE, Wong RJ, Aylor DA, Montem TW, Gudas JP (1990) Development and certification of HSLA-100 steel for naval ship construction. Nav Eng J 102(3):63-82

104. Dhua SK, Mukerjee D, Sarma DS (2002) Weldability and microstructural aspects of shielded metal arc welded HSLA100 steel plates. ISIJ Int 42(3):290-298. https://doi.org/10. 2355/isijinternational.42.290

105. Sun GF, Yao S, Wang ZD, Shen XT, Yan Y, Zhou R, Ni ZH (2018) Microstructure and mechanical properties of HSLA100 steel repaired by laser metal deposition. Surf Coat Technol 351:198-211. https://doi.org/10.1016/j.surfcoat.2018.07.048

106. Four stroke piston repair by laser cladding. Accessed 14/09/2020 https://www.kimi-sa.com/marine-shiprepairs/diesel-engine-machinery/four-stroke-piston-repair/

107. Koehler H, Partes K, Seefeld T, Vollertsen F (2010) Laser reconditioning of crankshafts: from lab to application. Proceedings of the Lane Laser Assisted Net Shape Engineering 6(5):387-397. https://doi.org/10.1016/j.phpro.2010.08.160 
108. Torims $\mathrm{T}$ (2013) The application of laser cladding to mechanical component repair, renovation and regeneration. Daaam international scientific book 12:587-608

109. Girsch G, Jörg A, Schoech W (2010) Managing rail life to match performance and cut costs. Railw Gaz Int 166(8):45-48

110. Clare A, Oyelola O, Folkes J, Farayibi P (2012) Laser cladding for railway repair and preventative maintenance. J Laser Appl 24(3):032004. https://doi.org/10.2351/1.4710578

111. Cannon DF, Edel KO, Grassie SL, Sawley K (2003) Rail defects: an overview. Fatigue Fract Eng Mater Struct 26(10):865-886. https://doi.org/10.1046/j.1460-2695.2003.00693.x

112. Lewis SR, Lewis R, Fletcher DI (2015) Assessment of laser cladding as an option for repairing/enhancing rails. Wear 330:581591. https://doi.org/10.1016/j.wear.2015.02.027

113. Zhu Y, Yang Y, Mu X, Wang W, Yao Z, Yang H (2019) Study on wear and RCF performance of repaired damage railway wheels: assessing laser cladding to repair local defects on wheels. Wear 430:126-136. https://doi.org/10.1016/j.wear.2019.04.028

114. Sexton L (2003) Laser cladding: repairing and manufacturing metal parts and tools. Opto-Ireland 2002. Adv Opt Photonics 4876:462-469

115. Nowotny S, Spatzier J, Kubisch F, Scharek S, Ortner J, Beyer E (2012) Repair of erosion defects in gun barrels by direct laser deposition. J Therm Spray Technol 21(6):1173-1183. https:// doi.org/10.1007/s11666-012-9817-3

116. Onuike B, Bandyopadhyay A (2019) Additive manufacturing in repair: influence of processing parameters on properties of Inconel 718. Mater Lett 252:256-259. https://doi.org/10.1016/j. matlet.2019.05.114

117. Graf B, Gumenyuk A, Rethmeier M (2012) Laser metal deposition as repair technology for stainless steel and titanium alloys. LANE 39:376-381. https://doi.org/10.1016/j.phpro.2012.10.051

118. Oh WJ, Lee WJ, Kim MS, Jeon JB, Shim DS (2019) Repairing additive-manufactured 316L stainless steel using direct energy deposition. Opt Laser Technol 117:6-17. https://doi.org/10. 1016/j.optlastec.2019.04.012

119. Sun GF, Shen XT, Wang ZD, Zhan MJ, Yao S, Zhou R, Ni ZH (2019) Laser metal deposition as repair technology for 316L stainless steel: influence of feeding powder compositions on microstructure and mechanical properties. Opt Laser Technol 109:71-83. https://doi.org/10.1016/j.optlastec.2018.07.051

120. Carroll BE, Otis RA, Borgonia JP, Suh JO, Dillon RP, Shapiro AA, Hofmann DC, Liu ZK, Beese AM (2016) Functionally graded material of 304L stainless steel and inconel 625 fabricated by directed energy deposition: characterization and thermodynamic modeling. Acta Mater 108:46-54. https://doi.org/10.1016/j.actamat.2016.02. 019

121. Mahamood RM, Akinlabi ET (2017) Types of functionally graded materials and their areas of application. In: Functionally graded materials. Springer pp 9-21

122. Jackson TR, Liu H, Patrikalakis NM, Sachs EM, Cima MJ (1999) Modeling and designing functionally graded material components for fabrication with local composition control. Mater Des 20(2-3):63-75. https://doi.org/10.1016/S0261-3069(99)00011-4

123. Kim DK, Woo W, Kim EY, Choi SH (2019) Microstructure and mechanical characteristics of multi-layered materials composed of $316 \mathrm{~L}$ stainless steel and ferritic steel produced by direct energy deposition. J Alloy Compd 774:896-907. https://doi.org/ 10.1016/j.jallcom.2018.09.390

124. Zhang XC, Chen YT, Liou F (2019) Fabrication of SS316LIN625 functionally graded materials by powder-fed directed energy deposition. Sci Technol Weld Joining 24(5):504-516. https://doi.org/10.1080/13621718.2019.1589086

125. Zhang X, Chen Y, Pan T, Cui W, Li L, Liou F (2019) Joining of copper and stainless steel 304L using direct metal deposition. SFF 6061:1068-1081
126. Aydogan B, O’Neil A, Sahasrabudhe H (2021) Microstructural and mechanical characterization of stainless steel 420 and Inconel 718 multi-material structures fabricated using laser directed energy deposition. J Manuf Process 68:1224-1235. https://doi.org/10.1016/j.jmapro.2021.06.031

127. Pan T, Zhang XC, Yamazaki T, Sutton A, Cui WY, Li L, Liou F (2020) Characteristics of Inconel 625-copper bimetallic structure fabricated by directed energy deposition. Int J Adv Manuf Technol 109(5-6):1261-1274. https://doi.org/10.1007/ s00170-020-05713-Z

128. Yao J, Xin B, Gong Y, Cheng G (2021) Effect of initial temperature on the microstructure and properties of Stellite-6/ Inconel 718 functional gradient materials formed by laser metal deposition. Materials (Basel) 14(13). https://doi.org/ 10.3390/ma14133609

129. Obielodan J, Stucker B (2013) Characterization of LENSfabricated Ti6Al4V and Ti6Al4V/TiC dual-material transition joints. Int J Adv Manuf Technol 66(9-12):2053-2061. https:// doi.org/10.1007/s00170-012-4481-9

130. Li Y, Feng ZY, Hao L, Huang LJ, Xin CX, Wang YS, Bilotti E, Essa K, Zhang H, Li Z, Yan FF, Peijs T (2020) A review on functionally graded materials and structures via additive manufacturing: from multi-scale design to versatile functional properties. AdvMat Technol 5(6):1900981. https://doi.org/10.1002/admt. 201900981

131. Mahamood RM, Akinlabi ET (2017) Processing methods of functionally graded materials. In: Functionally graded materials. Springer pp. 23-45

132. Mahamood RM, Akinlabi ET, Shukla M, Pityana S (2012) Functionally graded material: an overview

133. Hofmann DC, Kolodziejska J, Roberts S, Otis R, Dillon RP, Suh JO, Liu ZK, Borgonia JP (2014) Compositionally graded metals: a new frontier of additive manufacturing. J Mater Res 29(17):1899-1910. https://doi.org/10.1557/jmr.2014.208

134. Yan L, Chen YT, Liou F (2020) Additive manufacturing of functionally graded metallic materials using laser metal deposition. Addit Manuf 31. https://doi.org/10.1016/j.addma.2019.100901

135. Alcisto J, Enriquez A, Garcia H, Hinkson S, Steelman T, Silverman E, Valdovino P, Gigerenzer H, Foyos J, Ogren J, Dorey J, Karg K, McDonald T, Es-Said OS (2011) Tensile properties and microstructures of laser-formed Ti-6Al-4V. J Mater Eng Perform 20(2):203212. https://doi.org/10.1007/s11665-010-9670-9

136. Brandl E, Baufeld B, Leyens C, Gault R (2010) Additive manufactured Ti-6Al-4V using welding wire: comparison of laser and arc beam deposition and evaluation with respect to aerospace material specifications. Phys Procedia 5:595-606. https://doi.org/ 10.1016/j.phpro.2010.08.087

137. Budinski KG (1991) Tribological properties of titanium-alloys. Wear 151(2):203-217. https://doi.org/10.1016/0043-1648(91)90249-T

138. Kim YJ, Chung H, Kang SJL (2002) Processing and mechanical properties of Ti-6Al-4V/TiC in situ composite fabricated by gas-solid reaction. Mater Sci Eng, A 333(1-2):343-350. https:// doi.org/10.1016/S0921-5093(01)01858-5

139. Zhu J, Liaw P, Corum J, McCoy H (1999) High-temperature mechanical behavior of Ti-6Al-4V alloy and TiC p/Ti-6Al-4V composite. Metall and Mater Trans A 30(6):1569-1578

140. Zhang JW, Zhang YL, Li W, Karnati S, Liou F, Newkirk JW (2018) Microstructure and properties of functionally graded materials Ti6Al4V/TiC fabricated by direct laser deposition. Rapid Prototyp J 24(4):677-687. https://doi.org/10.1108/ Rpj-12-2016-0215

141. Mahamood RM, Akinlabi ET (2015) Laser metal deposition of functionally graded Ti6Al4V/TiC. Mater Des 84:402-410. https://doi.org/10.1016/j.matdes.2015.06.135 
142. Mahamood RM, Akinlabi ET, Shukla M, Pityana S (2014) Process for manufacture of titanium based composite. SA Patent No. 2014/03117

143. Roy R, Agrawal DK, Mckinstry HA (1989) Very Low thermalexpansion coefficient materials. Annu Rev Mater Sci 19(1):5981. https://doi.org/10.1146/annurev.ms.19.080189.000423

144. Bobbio LD, Otis RA, Borgonia JP, Dillon RP, Shapiro AA, Liu ZK, Beese AM (2017) Additive manufacturing of a functionally graded material from Ti-6Al-4V to Invar: experimental characterization and thermodynamic calculations. Acta Mater 127:133-142. https://doi.org/10.1016/j.actamat.2016.12.070

145. Ellis DL, Keller DJ, Nathal M (2000) Thermophysical properties of GRCop-84

146. Onuike B, Heer B, Bandyopadhyay A (2018) Additive manufacturing of Inconel 718-copper alloy bimetallic structure using laser engineered net shaping (LENS (TM)). Addit Manuf 21:133-140. https://doi.org/10.1016/j.addma.2018.02.007

147. Ellis DL (2005) GRCop-84: a high-temperature copper alloy for high-heat-flux applications

148. Thivillon L, Bertrand P, Laget B, Smurov I (2009) Potential of direct metal deposition technology for manufacturing thick functionally graded coatings and parts for reactors components. $\mathrm{J}$ Nucl Mater 385(2):236-241. https://doi.org/10.1016/j.jnucmat. 2008.11.023

149. Itel'man V (1978) Effect of the hardness on the service life of die-casting molds for aluminum alloys. Met Sci Heat Treat 20(10):861-862

150. Buchmayr B (2016) Damage, lifetime, and repair of forging dies. BHM Berg- Huettenmaenn Monatsh 162(3):88-93. https://doi. org/10.1007/s00501-016-0566-3

151. Elbestawi M, Chen L, Becze C, El-Wardany T (1997) High-speed milling of dies and molds in their hardened state. CIRP Ann 46(1):57-62

152. Tekmen C, Toparli M, Ozdemir I, Kusoglu IM, Onel K (2005) High temperature behaviour of $\mathrm{H} 13$ steel. Zeitschrift Fur Metallkunde 96(12):1431-1433. https://doi.org/10.3139/146.101196

153. Ayers JD (1984) Wear behavior of carbide-injected titanium and aluminum-alloys. Wear 97(3):249-266. https://doi.org/10.1016/ 0043-1648(84)90152-2

154. Jiang W, Molian P (2002) Laser based flexible fabrication of functionally graded mould inserts. Int J Adv Manuf Technol 19(9):646-654. https://doi.org/10.1007/s001700200109

155. Jiang WP, Nair R, Molian P (2005) Functionally graded mold inserts by laser-based flexible fabrication: processing modeling, structural analysis, and performance evaluation. J Mater Process Technol 166(2):286-293. https://doi.org/10.1016/j.jmatprotec. 2004.08.029

156. Zhang YZ, Wei ZM, Shi LK, Xi MZ (2008) Characterization of laser powder deposited Ti-TiC composites and functional gradient materials. J Mater Process Technol 206(1-3):438-444. https://doi.org/10.1016/j.jmatprotec.2007.12.055

157. Chen CJ, Xu X, Cao Q, Zhang M, Chang QM, Zhang SC (2012) Laser surface cladding of plastic-molded steel $718 \mathrm{H}$ by $\mathrm{CoCrMo}$ alloy. J Mater Eng Perform 21(6):946-950. https://doi.org/10. 1007/s11665-011-9993-1

158. Articek U, Milfelner M, Anzel I (2013) Synthesis of functionally graded material H13/Cu by LENS technology. Adv Prod Eng 8(3):169-176. https://doi.org/10.14743/apem2013.3.164

159. Ahn DG, Kim HW (2010) Study on the manufacture of a thermal management mould with three different materials using a direct metal tooling rapid tooling process. Proc Inst Mech Eng B J Eng Manuf 224(B3):385-402. https://doi.org/10.1243/ 09544054jem 1523

160. Cui CY, Guo ZX, Liu YH, Xie QQ, Wang Z, Hu JD, Yao Y (2007) Characteristics of cobalt-based alloy coating on tool steel prepared by powder feeding laser cladding. Opt Laser Technol
39(8):1544-1550. https://doi.org/10.1016/j.optlastec.2006.12. 005

161. Zhang XC, Pan T, Chen YT, Li L, Zhang YL, Liou F (2021) Additive manufacturing of copper-stainless steel hybrid components using laser-aided directed energy deposition. J Mater Sci Technol 80:100-116. https://doi.org/10.1016/j.jmst.2020.11.048

162. Noecker FF, DuPont JN (2002) Functionally graded copper-steel using laser engineered net shaping process. Solid Freeform Fabr Symp Proc pp. 231-238

163. Beal VE, Erasenthiran P, Hopkinson N, Dickens P, Ahrens CH (2006) The effect of scanning strategy on laser fusion of functionally graded $\mathrm{H} 13 / \mathrm{Cu}$ materials. Int J Adv Manuf Technol 30(9-10):844-852. https://doi.org/10.1007/s00170-005-0130-x

164. Fessler J, Nickel A, Link G, Prinz F, Fussell P (1997) Functional gradient metallic prototypes through shape deposition manufacturing. Solid Freeform Fabr Symp Proc

165. Trelewicz JR, Halada GP, Donaldson OK, Manogharan G (2016) Microstructure and corrosion resistance of laser additively manufactured 316L stainless steel. Jom 68(3):850-859. https://doi.org/ 10.1007/s11837-016-1822-4

166. Saboori A, Piscopo G, Lai M, Salmi A, Biamino S (2020) An investigation on the effect of deposition pattern on the microstructure, mechanical properties and residual stress of $316 \mathrm{~L}$ produced by directed energy deposition. Mater Sci Eng A:139179

167. Li XC, Stampfl J, Prinz FB (2000) Mechanical and thermal expansion behavior of laser deposited metal matrix composites of Invar and TiC. Mater Sci Eng, A 282(1-2):86-90. https://doi. org/10.1016/S0921-5093(99)00781-9

168. Kim TH, Chung JH (1997) Fabrication of functionally gradient materials in Inconel/Steel system by laser beam. Mater Trans, JIM 38(11):1010-1015. https://doi.org/10.2320/matertrans1989. 38.1010

169. Zhao SQ, Xie XS, Smith GD (2004) The oxidation behavior of the new nickel-based superalloy Inconel 740 with and without Na2SO4 deposit. Surf Coat Technol 185(2-3):178-183. https:// doi.org/10.1016/j.surfcoat.2003.12.003

170. Jian L, Yuh CY, Farooque M (2000) Oxidation behavior of superalloys in oxidizing and reducing environments. Corros Sci 42(9):1573-1585. https://doi.org/10.1016/S0010-938x(00) 00011-1

171. Savitha U, Reddy GJ, Venkataramana A, Rao AS, Gokhale AA, Sundararaman M (2015) Chemical analysis, structure and mechanical properties of discrete and compositionally graded SS316-IN625 dual materials. Mater Sci Eng, A 647:344-352. https://doi.org/10.1016/j.msea.2015.09.001

172. Mirzana IM, Rao GKM, Raheman SU, Ahmed MZ (2016) Fabrication and micro-structural study of functionally graded material disc of SS316/IN625. Mater Today 3(10):4236-4241

173. Liu YF, Weng F, Bi GJ, Chew YX, Liu SB, Ma GY, Moon SK (2019) Characterization of wear properties of the functionally graded material deposited on cast iron by laser-aided additive manufacturing. Int J Adv Manuf Technol 105(10):4097-4105. https://doi.org/10.1007/s00170-019-03414-w

174. Baghjari SH, Mousavi SAAA (2013) Effects of pulsed Nd: YAG laser welding parameters and subsequent post-weld heat treatment on microstructure and hardness of AISI 420 stainless steel. Mater Des 43:1-9. https://doi.org/10.1016/j.matdes.2012.06.027

175. Chen B, Su Y, Xie ZH, Tan CW, Feng JC (2020) Development and characterization of $316 \mathrm{~L} / \mathrm{Incone} 625$ functionally graded material fabricated by laser direct metal deposition. Opt Laser Technol 123:105916. https://doi.org/10.1016/j.optlastec.2019. 105916

176. Wu D, Liang X, Li Q, Jiang L (2010) Laser rapid manufacturing of stainless steel 316L/Inconel718 functionally graded materials: microstructure evolution and mechanical properties. Int J Opt 
177. Shah K, ul Haq I, Khan A, Shah SA, Khan M, Pinkerton AJ, (2014) Parametric study of development of Inconel-steel functionally graded materials by laser direct metal deposition. Mater Des 54:531-538. https://doi.org/10.1016/j.matdes.2013.08.079

178. Balla VK, Banerjee S, Bose S, Bandyopadhyay A (2010) Direct laser processing of a tantalum coating on titanium for bone replacement structures. Acta Biomater 6(6):2329-2334. https:// doi.org/10.1016/j.actbio.2009.11.021

179. Bandyopadhyay A, Krishna BV, Xue W, Bose S (2009) Application of laser engineered net shaping (LENS) to manufacture porous and functionally graded structures for load bearing implants, J Mater Sci Mater Med 20 Suppl 1(1):S29-34. https:// doi.org/10.1007/s10856-008-3478-2

180. Bandyopadhyay A, Balla VK, Roy M, Bose S (2011) Laser surface modification of metallic biomaterials. Jom 63(6):94-99. https://doi.org/10.1007/s11837-011-0099-x

181. Krishna BV, Xue WC, Bose S, Bandyopadhyay A (2008) Functionally graded Co-Cr-Mo coating on Ti-6Al-4V alloy structures. Acta Biomater 4(3):697-706. https://doi.org/10.1016/j.actbio. 2007.10.005

182. Janaki Ram G, Yang Y, Stucker B (2007) Deposition of Ti/TiC composite coatings on implant structures using laser engineered net shaping. Solid Freeform Fabr Symp Proc

183. Piscopo G, Salmi A, Atzeni E, Iuliano L, Busatto M, Tusacciu S, Lai M, Biamino S, Toushekhah M, Saboori A (2019) On the effect of deposition patterns on the residual stress, roughness and microstructure of AISI 316L samples produced by directed energy deposition. Proc Int Conf Prog Addit Manuf 206-212

184. Lindemann C, Jahnke U, Moi M, Koch R (2012) Analyzing product lifecycle costs for a better understanding of cost drivers in additive manufacturing. Solid Freeform Fabr Symp Proc. Austin Texas USA 6th-8th August

185. Ford S, Despeisse M (2016) Additive manufacturing and sustainability: an exploratory study of the advantages and challenges. J Clean Prod 137:1573-1587. https://doi.org/10.1016/j.jclepro. 2016.04.150

186. ASTM A473 - 21, Standard specification for stainless steel forgings, ASTM International, West Conshohocken, PA, 2021

187. ML Griffith MT Ensz JD Puskar CV Robino JA Brooks JA Philliber JE Smugeresky WH Hofmeister 2011 Understanding the microstructure and properties of components fabricated by laser engineered net shaping (LENS) MRS Proc 625 https://doi. org/10.1557/proc-625-9

188. Mazzucato F, Forni D, Valente A, Cadoni E (2021) Laser metal deposition of Inconel 718 alloy and as-built mechanical properties compared to casting. Materials (Basel) 14(2). https://doi.org/ $10.3390 / \mathrm{ma} 14020437$

189. Najmon JC, Raeisi S, Tovar A (2019) Review of additive manufacturing technologies and applications in the aerospace industry. In: Additive manufacturing for the aerospace industry. Elsevier pp 7-31. Accessed 10/09/2020 https://www.openelectronics.org/5-meter-long-titanium-airplane-part-is-3dprinted-in-one-piece/

190. Mori D (2014) Additive manufacturing in milling quality

191. Hauser C (2014) Case study: laser powder metal deposition manufacturing of complex real parts. http://www.lortek.es/files/ merlin/05-C_Hauser-TWI-Case-Study.pdf
192. Mori DMG https://uk.dmgmori.com/

193. TWI https://www.twi-global.com

194. Optomec (2016) Top ten industrial additive manufacturing applications. Accessed 3 December 2021 https://www.optomec.com/ wp-content/uploads/2016/04/TopTen-Additive-ManufacturingApps.pdf

195. Ma MM, Wang ZM, Wang DZ, Zeng XY (2013) Control of shape and performance for direct laser fabrication of precision largescale metal parts with 316L stainless steel. Opt Laser Technol 45:209-216. https://doi.org/10.1016/j.optlastec.2012.07.002

196. United States International Trade Commission (2002) Tools dies, and industrial molds: competitive conditions in the United States and selected foreign markets. US International Trade Commission

197. (2008) DMD conformal mold cooling lines offer reduced part production cycle times. https://www.moldmakingtechnology.com/ columns/dmd-conformal-mold-cooling-lines-offer-reduced-partproduction-cycle-times

198. Ahsan MN, Paul CP, Kukreja LM, Pinkerton AJ (2011) Porous structures fabrication by continuous and pulsed laser metal deposition for biomedical applications; modelling and experimental investigation. J Mater Process Technol 211(4):602-609. https:// doi.org/10.1016/j.jmatprotec.2010.11.014

199. Palčič I, Balažic M, Milfelner M, Buchmeister B (2009) Potential of laser engineered net shaping (LENS) technology. Mater Manuf Processes 24(7-8):750-753

200. Dinda GP, Song L, Mazumder J (2008) Fabrication of Ti-6Al-4V scaffolds by direct metal deposition. Metall Mater Trans A Phys Metall Mater Sci 39a(12):2914-2922. https://doi.org/10.1007/ s11661-008-9634-y

201. Krishna BV, Bose S, Bandyopadhyay A (2007) Low stiffness porous Ti structures for load-bearing implants. Acta Biomater 3(6):997-1006. https://doi.org/10.1016/j.actbio.2007.03.008

202. Xue L, Theriault A, Rubinger B, Parry D, Ranjbaran F (2003) Doyon M (2003) Investigation of laser consolidation process for manufacturing structural components for advanced robotic mechatronics system (ARMS). International Congress on Applications of Lasers \& Electro-Optics 1:909

203. Xue L, Theriault A, Chen J-Y, Islam M, Wieczorek A, Draper G (2001) Laser consolidation of CPM-9 V tool steel for the manufacturing of rotary cutting dies. Solid Freeform Fabr Symp Proc $\mathrm{X}: 361-376$

204. Xue L (2018) Laser consolidation-a rapid manufacturing process for making net-shape functional components. Elsevier. Lasers Manuf Mater Process pp. 461-505

205. Xue L (2006) Purcell C (2006) Laser consolidation of net-shape shells for flextensional sonar projectors. ICALEO 1:1206

Publisher's Note Springer Nature remains neutral with regard to jurisdictional claims in published maps and institutional affiliations. 